\title{
A New Approach for Spherical Fuzzy TOPSIS and Spherical Fuzzy VIKOR Applied to the Evaluation of Hydrogen Storage Systems
}

Iman Mohamad Sharaf ( $\square$ iman_sharaf@hotmail.com )

Higher Technological Institute https://orcid.org/0000-0002-0878-5696

\section{Research Article}

Keywords: multi-criteria decision making, TOPSIS, VIKOR, spherical fuzzy sets, warehouse selection problem, hydrogen storage systems

Posted Date: January 7th, 2022

DOI: https://doi.org/10.21203/rs.3.rs-1025439/v1

License: (c) (i) This work is licensed under a Creative Commons Attribution 4.0 International License.

Read Full License 


\title{
A new approach for spherical fuzzy TOPSIS and spherical fuzzy VIKOR applied to the evaluation of hydrogen storage systems
}

\author{
Iman Mohamad Sharaf* \\ Department of Basic Sciences \\ Higher Technological Institute, \\ Tenth of Ramadan City, Egypt. \\ iman_sharaf@hotmail.com \\ $+201063075719$ \\ ORCID:0000-0002-0878-5696
}




\title{
A new approach for spherical fuzzy TOPSIS and spherical fuzzy VIKOR applied to the evaluation of hydrogen storage systems
}

\begin{abstract}
This study proposes a new perspective of the TOPSIS and VIKOR methods using the recently introduced spherical fuzzy sets (SFSs) to handle the vagueness in subjective data and the uncertainties in objective data simultaneously. When implementing these techniques using SFSs, two main problems might arise that can lead to incorrect results. Firstly, the reference points might change with the utilized score function. Secondly, the distance between reference points might not be the largest, as known, among the available ratings. To overcome these deficiencies and increase the robustness of these two methods, they are implemented without utilizing any reference points to minimize the effect of defuzzification and without measuring the distance to eliminate the effect of distance formulas. In the proposed methods, when using an SFS to express the performance of an alternative for a criterion, this SFS per se can be viewed as a measure of proximity to the aspired level. On the other hand, the conjugate of the SFS can be viewed as a measure of proximity to the ineffectual level. Two practical applications are presented to demonstrate the proposed techniques. The first example handles a warehouse location selection problem. The second example evaluates hydrogen storage systems for automobiles with different types of data (crisp, linguistic variables, type 1 fuzzy sets). These data are transformed to SFSs to provide a more comprehensive analysis. A comparative study is conducted with earlier versions of TOPSIS and VIKOR to explicate the adequacy of the proposed methods and the consistency of the results.
\end{abstract}

Keywords: multi-criteria decision making; TOPSIS; VIKOR; spherical fuzzy sets; warehouse selection problem; hydrogen storage systems

\section{Introduction}

When designing sustainable technologies and products, multiple conflicting objectives are often encountered. For example, the design of cleaner technologies is costly (Zhang et al. 2019). For this reason, multi-criteria decision-making (MCDM) has become an important issue and a necessary approach to handle such situations, being capable of surpassing the obstacles associated with such trade-offs.

When rating the performance of alternatives under consideration for the evaluation criteria, the information is often imprecise due to the nature of data, measurement errors, or the nature of the underlying research questions. For example, 
experts' subjective data might be associated with different degrees of certainty based on their confidence (Zhang et al. 2019).

Since 1965, the fuzzy set theory has been successfully applied in real-life problems with imprecise, vague, or uncertain data. Several researchers developed other types of fuzzy sets besides Zadeh's type 1 (T1FSs) and type 2 (T2FSs) ordinary fuzzy sets (Zadeh 1965, 1975). Among the proposed fuzzy sets: intuitionistic fuzzy sets (IFSs), Pythagorean fuzzy sets (PFSs), neutrosophic fuzzy sets (NFSs), hesitant fuzzy sets (HFSs), and spherical fuzzy sets (SFSs). These extensions have been utilized in solving various MCDM problems.

Atanassov (1986) introduced IFSs to convey the support of the decision-makers (DMs), opposition, and indeterminacy simultaneously. IFSs can express these states and model human perception efficiently whenever imprecision and uncertainty are salient in the problem's domain. IFSs have two independent dimensions: the membership degree and the non-membership degree. The third dimension "the hesitancy degree" depends on the other two dimensions such that their sum is equal to one. In some cases, IFSs are unable to express the DMs opinion and demonstrate the current status. Thereafter, two extensions were proposed to overcome IFSs drawbacks.

Smarandache (1998) extended the concept of (IFSs) to NFSs. An NFS consists of three degrees: truth, falsity, and indeterminacy. The degree of indeterminacy is treated as a new and independent component of the set. This independent indeterminacy parameter gives more details in the membership function and depicts real-life problems more accurately. The sum of these degrees can be between 0 and 3, and the value of each degree can be between 0 and 1, independently. Consequently, using NFSs in decisionmaking can produce better results. Despite that, an NFS is difficult to apply in real scientific and engineering fields (Boltürk and Kahraman 2018).

Yager (2014) generalized IFSs to type-2 IFSs (T2IFSs), also known as Pythagorean fuzzy sets (PFSs), to handle the conditions in which IFSs are incompetent. The difference between PFSs and IFSs is the constraint on the sum of the three dimensions. The constraint is modified such that the sum of the squares of the three degrees is equal to one.

Gündoğdu and Kahraman (2019a) proposed SFSs to define the experts' judgement in more details. SFSs are a sort of merging PFSs and NFSs. They are characterized by a membership degree, a non-membership degree, and a hesitancy degree. Similar to NFSs, the hesitancy degree is independent. Meanwhile, the sum of the squares of these degrees is between 0 and 1 . Hence, SFSs can handle the information of type: yes, no, abstain and refusal, owing to the feature of broad space of admissible triplets. This remarkable feature of SFSs to manage the uncertainty and ambiguity distinguishes it from other fuzzy set models (Akram et al. 2020). Being able to reflect human cognition; they provide the DMs with a flexible structure that can effectively capture fuzziness and uncertainty. 
Later, the concept of complex spherical fuzzy sets (CSFSs) was introduced as an extended version of SFSs in which the range of degrees occurs in the complex plane with unit disk (Akram et al. 2021a, b, c).

MCDM encompass a variety of methods that can handle the complexity of decision-making problems. According to Liao and Xu (2014), these methods are classified into two main categories: outranking methods (OMs) and utility theory-based methods (UBMs). OMs depend on pairwise comparisons and dominance relations to identify whether an alternative is indifferent, preferable, or incomparable to another alternative for the evaluation criteria. Meanwhile, UBMs depend on merging the evaluation values of each alternative over various criteria into an overall index which is used to rank the alternatives. Various MCDM methods were extended in the spherical fuzzy environment to handle problems arising in a wide range of applications due to the superiority of SFSs in expressing vagueness and uncertainty (Boltürk 2020; Gül 2021; Donyatalab et al. 2021; Erdoğan et al. 2021; Gündoğdu and Kahraman 2019 a, b; Gündoğdu and Kahraman 2020a, b; Hamal and Ozlem 2021; Sharaf 2021a, b; Sharaf and Khalil 2021).

The Technique of Order Preference by Similarity to an Ideal Solution (TOPSIS) and VIsekriterijumska optimizacija i KOmpromisno Resenje (VIKOR) are two wellknown and successful MCDM techniques. They belong to the class of UBMs. The idea of both methods is based on the proximity to the optimal solution. The evaluation system relies on the distances from two reference points, i.e. the best and worst solutions. Despite the similarity that might appear between the two methods, they use different aggregation functions and different normalization methods. TOPSIS and VIKOR were extended in the fuzzy environment using all the previously mentioned fuzzy sets.

In a fuzzy environment, TOPSIS and VIKOR rest on two main pillars, defuzzification formulas and distance formulas. In the spherical fuzzy environment, to implement SF-TOPSIS and SF-VIKOR we face two main concerns with these two pillars. First, early defuzzification is required to determine the positive and negative ideal solutions (Gündoğdu and Kahraman 2019a, 2019b). So far, several score functions were proposed (Gündoğdu and Kahraman 2019a, b; 2020a; Sharaf 2021b; Sharaf and Khalil 2021). These newly developed score functions might affect the rankings since they have not been widely researched as SFSs are recently introduced (Gündoğdu and Kahraman $2020 \mathrm{~b}$ ). Then, the reference points might change with the utilized score function. Second, as is well known, the distance between the positive and negative ideal solutions is the largest distance among the available ratings. However, this basic concept might not be valid for some distance formulas in the spherical fuzzy environment, i.e. the distance between the reference points might not be the largest distance among the available ratings. These two concerns might affect these two methods and might give incorrect results. To overcome these deficiencies and increase the robustness of SF-TOPSIS and 
SF-VIKOR, it is required to implement these methods in a way that reduces the effect of both defuzzification and distance formulas.

So far, in the problems treated in the spherical fuzzy environment, the ratings of the alternatives for the criteria are expressed by SFSs solely. In many applications, the data of the performance are both subjective judgement and objective data. Therefore, it is required to mingle both types of data in the spherical fuzzy environment.

In this study, TOPSIS and VIKOR are extended in the spherical fuzzy environment to address the vagueness associated with subjective judgements and the uncertainties associated with the objective data simultaneously. To minimize the effect of defuzzification and distance formulas, SF-TOPSIS and SF-VIKOR techniques are implemented without using any reference point and without using the distance as a measure. This increases the robustness of these techniques. When an SFS is used to express the performance of an alternative for a criterion, this SFS per se can be viewed as a measure of proximity to the aspired level. On the other hand, the conjugate of the SFS can be viewed as a measure of proximity to the ineffectual level. Two practical applications are presented to demonstrate the proposed techniques and show their applicability. The first example handles a warehouse location selection problem in which both the weights of the criteria and the ratings of the alternatives for the chosen criteria are expressed by SFSs. The second example evaluates hydrogen storage systems for automobiles. In this example, the weights of the criteria are type 1 fuzzy sets while the ratings of the alternatives for the evaluation criteria are crisp and linguistic variables.

The main contribution of the article can be summarized as follows.

- First, provide a flexible framework that handles different types of data for MCDM. TOPSIS and VIKOR are proposed in the context of data merging due to the lack of techniques that can handle hybrid uncertainties properly within an evaluation system. Different types of data sets (crisp, linguistic variables, type 1 fuzzy sets) are transformed to SFSs. Therefore, a more comprehensive analysis of the available alternatives with different patterns of uncertainty and vagueness can be conducted.

- Second, TOSIS and VIKOR are implemented, for the first time, without relying on reference points. Thus, the proposed techniques form a robust platform that can guide DMs during the evaluation process due to the elimination of distance formulas, and the effect of defuzzification is reduced.

- Third, they enable DMs to express their hesitation in the decision-making process by using a linguistic assessment scale based on SFSs. Integrating the advantages of both PFSs and NFSs makes these techniques more powerful in handling vagueness and imprecision.

The article is organized as follows. A literature review on TOPSIS and VIKOR is summarized in section 2. Section 3 includes the preliminaries of SFSs, the conventional TOPSIS, and the conventional VIKOR. The proposed Sf-TOPSIS and SF-VIKOR are introduced in Section 4. In section 5, the proposed techniques are applied to two 
applications, warehouse selection problem and hydrogen storage systems for automobiles. The conclusion and discussion are drawn in section 6 .

\section{A literature review}

\subsection{The TOPSIS method}

Ever since Hwang and Yoon (1981) introduced TOPSIS, it has been successfully applied in many technological, business, economics, and social applications. After the proposal of diverse types of fuzzy sets, TOPSIS was extended in the context of these sets. For a comprehensive survey on the fuzzy extensions of TOPSIS, the reader is referred to Salih et al. (2018). In addition, Palczewski and Sałabun (2019) provided a review of TOPSIS applications using different types of fuzzy sets in the past decade. Up to the present time, still several novel real-world problems are handled with ordinary fuzzy TOPSIS (F-TOPSIS), e.g. marketing on social network sites (Chu and Kysely 2020), credit scoring (Mehdiyev 2020), automated storage and retrieval systems technology (Boltürk 2020), and in the selection of political candidates in elections (Alguliyev et al. 2020). A review of the recent research on the fuzzy extensions of TOPSIS with different applications in the past two years is summarized as follows.

Han and Trimi (2018) used F-TOPSIS with FLINTSTONES, a software tool, to evaluate reverse logistics practices in social commerce platforms. Lupo and Bellomo (2019) integrated the DINESERV model along with the hierarchical TOPSIS method as a measurement tool for evaluating quality in the restaurant services context. Malakouti et al. (2019) utilized F-TOPSIS to rank the most crucial components of flexibility in the field of housing. Nilashi et al. (2019) developed a new decision-making model using a decision making trial and evaluation laboratory (DEMATEL) and F-TOPSIS to reveal the inter-relationships among the factors influencing the development of medical tourism in developing countries and evaluate their relative importance. Rashidi and Cullinane (2019) performed a comparative analysis of the outcomes achieved when the two widely used methods for supplier selection TOPSIS and data envelopment analysis (DEA) are applied to a common dataset of logistics service providers in Sweden. The results revealed that TOPSIS outperforms DEA in terms of both calculation complexity and sensitivity to changes in the number of suppliers. Seyedmohammadi et al. (2018) employed simple additive weighting (SAW), TOPSIS, and F-TOPSIS methods for evaluating areas suitable for cultivation priority planning of maize, rape and soybean crops in land units. Al Zaabi and Bashir (2020) proposed a novel approach that integrates social network analysis (SNA), F-TOPSIS, and cross-impact matrix multiplication applied to classification (MICMAC) to provide project managers with a holistic view of interdependencies among projects to classify projects in terms of their driving power and dependence power and out- and in-degree centrality. Rani et al. (2020a) proposed a new divergence measure for ranking and choosing the renewable energy sources in MCDM problems based on F-TOPSIS. Forouzandeh et al. (2021) proposed a novel approach to 
recommendation systems in the tourism industry involving a combination of the Artificial Bee Colony (ABC) algorithm and the F-TOPSIS model.

Hajek and Froelich (2019) integrated TOPSIS with fuzzy cognitive maps (FCMs) using interval-valued intuitionistic fuzzy sets (IVIFSs) to develop a tool that can model interactions among highly imprecise criteria. Memari et al. (2019) presented an IFTOPSIS method to select the right sustainable supplier for an automotive spare parts manufacturer. Garg and Kumar (2020) extended TOPSIS with IVIFSs using a new exponential distance and connection number of set pair analysis (SPA) theory. Rouyendegh et al. (2020) proposed a performance evaluation model for the retail industry through an IF-TOPSIS and data envelopment analysis (DEA). Yalcin et al. (2020) utilized IF-DEMATEL to illustrate the relationship between the criteria and to remove inefficient ones. Then, they applied IF-TOPSIS using the selected effective criteria to find the most appropriate alternative

Yu et al. (2019) developed a group decision making sustainable supplier selection approach using TOPSIS with interval-valued Pythagorean fuzzy sets (IVPFSs). Rani et al. (2020b) developed a PF-TOPSIS for solving sustainable recycling partner selection problems with completely unknown decision experts and criteria weights. Sarkar and Biswas (2020) presented an approach for solving Pythagorean fuzzy (PF) multi-criteria group decision-making problems with completely unknown weight information about criteria using entropy weight model, linear programming (LP) and TOPSIS. Yucesan and Gul (2020) presented a model based on PF-AHP and PF-TOPSIS to provide an accurate decision-making process for evaluating the hospital service quality.

Akram and Adeel (2019) developed a novel approach with interval-valued hesitant fuzzy N-soft sets (IVHFNSSs) and extended the method of TOPSIS.

Karaşan et al. (2020) integrated AHP and TOPSIS with NFSs for prioritizing the solution alternatives gathered by the United Nations to reach sustainable development goals and face common urban challenges. Karaşan and Kaya (2020) suggested a NFTOPSIS to evaluate and select the most appropriate network controller technology and relays of the Unmanned Aerial Vehicles (UAVs).

Gündoğdu and Kahraman (2019a) extended TOPSIS in the context of SFSs. They also developed TOPSIS with interval-valued spherical fuzzy sets and compared the performance of both techniques (Gündoğdu and Kahraman 2019c). Akram et al. (2021c) presented a strategy that combines the novel features of complex spherical fuzzy sets (CSFSs) that can handle the aspects of two-dimensional information involved in the nature of human decisions with the potential of the TOPSIS method.

\subsection{The VIKOR method}

VIKOR is one of the most successful and most extensively used MCDM methods. According to Gündoğdu and Kahraman (2019b) more than 4000 articles on VIKOR was published in the past decade. Opricovic (1998) introduced the first version of VIKOR to solve discrete MCDM problems with incommensurable and conflicting criteria. VIKOR 
proposes a compromise solution regarding these criteria while considering mutual concessions. A compromise solution is a feasible solution that is not only close to the ideal solution but also provides a maximum group utility for the majority and a minimum of an individual regret for the opponent. The conventional VIKOR has been extended using various fuzzy sets, e.g. T1FSs, T2FSs, IFSs, HFSs, NFSs and PFSs. For extensive surveys on VIKOR and its fuzzy extensions for various applications till the years 2014 and 2015, the reader is referred to Yazdani and Graeml (2014) and Gul et al. (2016). The most prominent extensions of VIKOR using diverse types of fuzzy sets from 2016 can be summarized according to the used fuzzy set as follows.

In the context of ordinary fuzzy sets, several types of research were presented using either triangular or trapezoidal T1FSs and interval type 2 fuzzy sets (IT2FSs). As for triangular T1FSs, Awasthi and Kannan (2016) evaluated green supplier development programs and proposed a fuzzy nominal group technique (F-NGT) with an F-VIKOR. Sari (2017) integrated the fuzzy analytical hierarch process (F-AHP), F-VIKOR, and Monte Carlo simulation in the assessment of green supply chain management practices. Emeç and Akkaya (2018) developed an MCDM approach using the stochastic AHP and F-VIKOR to solve a warehouse location problem. Gul et al. (2018) proposed a new risk assessment technique incorporating F-AHP with F-VIKOR. Zhou et al. (2018) applied an F-VIKOR based model in the construction of a robotic automation system in the healthcare industry. Li et al. (2020) proposed a machine tool selection method based on fuzzy decision-making trial and evaluation laboratory (F-DEMATEL) and later defuzzification VIKOR (LDVIKOR).

Employing IT2FSs, Ghorabaee (2016) proposed an F-VIKOR for robot selection in manufacturing. Soner et al. (2017) also integrated the F-AHP method with F-VIKOR to handle hatch cover design selection problems due to its importance in the structure of bulk carrier ships to prevent water ingress and protect cargo from external damages. Liu et al. (2018) integrated ANP (analytical network process) and F-VIKOR to solve a supplier selection problem. Sharaf (2019a) modified F-VIKOR to reduce the computations and to consider the decision-makers optimism level.

In the context of IFSs, Gupta et al. (2016) developed a novel IF-VIKOR to solve plant location selection problems using trapezoidal intuitionistic fuzzy numbers (TrIFNs). Mousavi et al. (2016) introduced an IF-VIKOR for portfolio selection in stock exchange problems and material handling selection problems. Luo and Wang (2017) proposed an IF-VIKOR for enterprise resource planning systems. Zhao et al. (2017) develop an IFhybrid VIKOR to solve supplier selection problems. Zeng et al. (2019) proposed a modified IF-VIKOR using a new score function which not only calculates the closest ideal score value of each alternative but also calculates the farthest worst score value of each alternative. Krishankumar et al. (2020) applied a new IF-VIKOR that combines the strength of both interval-valued fuzzy sets and IFS to a personnel selection problem. 
Utilizing PFSs, Chen (2018) proposed a PF-VIKOR methodology to handle two types of problems; the evaluation of service quality and internet stock performance, and internet stock and R\&D project investment problems. Cui et al. (2018) proposed a PFVIKOR approach to select the site of electric vehicle charging stations. Gul et al. (2019) improved the overall safety levels of underground mining using a PF-VIKOR by considering the potential hazards of risk management. Mete et al. (2019) developed a decision support system (DSS) based on PF-VIKOR in occupational risk assessment (ORA) and employed a case study to the risk assessment of a natural gas pipeline construction.

In the bi-dimensional dual hesitant fuzzy (BDHF) context, Xue et al. (2016) proposed an extension of fuzzy VIKOR to analyse the performance of people's livelihood projects in several regions. Narayanamoorthy and Geetha (2017) extended VIKOR for intuitionistic hesitant fuzzy sets (IHFSs) in which the degree of importance of each criterion is determined by the entropy method. Ren et al. (2017) developed a dual hesitant fuzzy (DHF) VIKOR to select a cooperative partner. Krishankumar et al. (2018) adopted linguistic hesitant fuzzy sets (LHFSs) for elicitation of preference information in sustainable healthcare management. Khan et al. (2019) proposed an extension of VIKOR with Pythagorean hesitant fuzzy sets (PHFSs).

$\mathrm{Hu}$ et al. (2017) established a projection-based VIKOR using interval neutrosophic fuzzy sets (INFSs) and employed the maximizing deviation method to obtain weights for the evaluation criteria in a mobile healthcare application. Huang et al. (2017) extend VIKOR with interval neutrosophic fuzzy sets (INFSs). Pramanik et al. (2018) proposed a VIKOR based strategy using bipolar neutrosophic fuzzy sets. AbdelBaset et al. (2019) proposed a novel technique composed of the ANP and VIKOR using triangular neutrosophic sets (TriNFSs) to deal with incomplete information and high order imprecision. Manna et al. (2020) developed a complex neutrosophic soft VIKOR approach to get a compromise optimal solution for problems with single as well as multiple decision-makers. Wang et al. (2018) extended VIKOR using TriNFSs for the potential evaluation of emerging technology commercialization. Liang et al. (2018) established a new framework based on the qualitative flexible (QUALIFLEX) method and VIKOR using linguistic neutrosophic number (LNN) to assess the performance of the circular economy for phosphorus chemical firms. Wei et al. (2019) extended VIKOR to interval-valued 2-tuple linguistic neutrosophic numbers (IV2TLNNs) for green supplier selection.

Finally, Gündoğdu and Kahraman (2019b) extended the VIKOR method to the spherical fuzzy environment to solve a warehouse location selection problem. Sharaf (2021a) implemented VIKOR using SFSs in four different ways based on two aggregation operators and two ideal solutions and the stability of the solution is examined under these different implementations. Akram et al. (2021a) presented a multi-skilled high potential multi-criteria group decision-making (MCGDM) technique, namely, 
complex spherical fuzzy VIKOR (CSF-VIKOR) based on the VIKOR method and motivated by the CSF model which is adequate to deal with two-dimensional data.

\section{Preliminaries}

\subsection{Spherical fuzzy sets}

An SFS is given by

$$
\tilde{A}_{s}=\left\{\left\langle u,\left(\mu_{\tilde{A}_{s}}(u), v_{\tilde{A}_{s}}(u), \pi_{\tilde{A}_{s}}(u)\right) \mid u \in U\right\rangle\right\},
$$

where

$\mu_{\tilde{A}_{S}}: U \rightarrow[0,1]$ is the membership degree, $v_{\tilde{A}_{S}}: U \rightarrow[0,1]$ is the non-membership degree, and $\pi_{\tilde{A}_{s}}: U \rightarrow[0,1]$ is the hesitancy degree.

These three degrees satisfy the condition

$$
0 \leq \mu_{\tilde{A}_{s}}^{2}(u)+v_{\tilde{A}_{s}}^{2}(u)+\pi_{\tilde{A}_{s}}^{2}(u) \leq 1, \forall u \in U .
$$

Gündoğdu and Kahraman (2019a) defined addition, multiplication, multiplication by a scalar, and exponentiation of SFSs as follows.

For two SFSs $\tilde{A}_{s}=\left(\mu_{\tilde{A}_{s}}, v_{\tilde{A}_{s}}, \pi_{\tilde{A}_{S}}\right)$ and $\tilde{B}_{S}=\left(\mu_{\tilde{B}_{S}}, v_{\tilde{B}_{S}}, \pi_{\tilde{B}_{S}}\right)$

$$
\begin{aligned}
& \tilde{A}_{s} \oplus \tilde{B}_{S}=\left\{\left(\mu_{\tilde{A}_{S}}^{2}+\mu_{\tilde{B}_{S}}^{2}-\mu_{\tilde{A}_{S}}^{2} \mu_{\tilde{B}_{S}}^{2}\right)^{1 / 2}, v_{\tilde{A}_{S}} v_{\tilde{B}_{S^{\prime}}}\left(\left(1-\mu_{\tilde{B}_{S}}^{2}\right) \pi_{\tilde{A}_{S}}^{2}+\left(1-\mu_{\tilde{A}_{S}}^{2}\right) \pi_{\tilde{B}_{S}}^{2}-\pi_{\tilde{A}_{S}}^{2} \pi_{\tilde{B}_{S}}^{2}\right)^{1 / 2}\right\} . \\
& \tilde{A}_{S} \otimes \tilde{B}_{S}=\left\{\mu_{\tilde{A}_{S}} \mu_{\tilde{B}_{S}}\left(v_{\tilde{A}_{S}}^{2}+v_{\tilde{B}_{S}}^{2}-v_{\tilde{A}_{S}}^{2} v_{\tilde{B}_{S}}^{2}\right)^{1 / 2},\left(\left(1-v_{\tilde{B}_{S}}^{2}\right) \pi_{\tilde{A}_{S}}^{2}+\left(1-v_{\tilde{A}_{S}}^{2}\right) \pi_{\tilde{B}_{S}}^{2}-\pi_{\tilde{A}_{S}}^{2} \pi_{\tilde{B}_{S}}^{2}\right)^{1 / 2}\right\} \text {. } \\
& \lambda \odot \tilde{A}_{s}=\left\{\left(1-\left(1-\mu_{\tilde{A}_{S}}^{2}\right)^{\lambda}\right)^{1 / 2}, v_{\tilde{A}_{s}}^{\lambda}\left(\left(1-\mu_{\tilde{A}_{S}}^{2}\right)^{\lambda}-\left(1-\mu_{\tilde{A}_{S}}^{2}-\pi_{\tilde{A}_{S}}^{2}\right)^{1 / 2}\right)\right\}, \lambda>0 . \\
& \tilde{A}_{S}^{\lambda}=\left\{\mu_{\tilde{A}_{s}}^{\lambda}\left(1-\left(1-v_{\tilde{A}_{S}}^{2}\right)^{\lambda}\right)^{1 / 2},\left(\left(1-v_{\tilde{A}_{S}}^{2}\right)^{\lambda}-\left(1-v_{\tilde{A}_{S}}^{2}-\pi_{\tilde{A}_{S}}^{2}\right)^{\lambda}\right)^{1 / 2}\right\}, \lambda>0 .
\end{aligned}
$$

Gündoğdu and Kahraman (2019a) also proposed two aggregation operators, the spherical weighted arithmetic mean (SWAM) and the spherical weighted geometric mean (SWGM) as follows.

$$
\begin{gathered}
\operatorname{SWAM}_{w}\left(\tilde{A}_{S_{1}}, \tilde{A}_{S_{2}}, \ldots, \tilde{A}_{S_{n}}\right)=w_{1} \tilde{A}_{S_{1}}+w_{2} \tilde{A}_{S_{2}}+\cdots+w_{n} \tilde{A}_{S_{n}}= \\
\left\{\left[1-\prod_{i=1}^{n}\left(1-\mu_{\tilde{A}_{S_{i}}}^{2}\right)^{w_{i}}\right]^{1 / 2}, \prod_{i=1}^{n} v_{\tilde{A}_{S_{i}}}^{w_{i}}\left[\prod_{i=1}^{n}\left(1-\mu_{\tilde{A}_{S_{i}}}^{2}\right)^{w_{i}}-\prod_{i=1}^{n}\left(1-\mu_{\tilde{A}_{S_{i}}}^{2}-\pi_{\tilde{A}_{S_{i}}}^{2}\right)^{w_{i}}\right]^{1 / 2}\right\},
\end{gathered}
$$

where $w_{i} \in[0,1] ; \sum_{i=1}^{n} w_{i}=1$.

$$
\begin{gathered}
\operatorname{SWGM}_{w}\left(\tilde{A}_{S_{1}}, \tilde{A}_{S_{2}}, \ldots, \tilde{A}_{S_{n}}\right)=\tilde{A}_{S_{1}}^{w_{1}}+\tilde{A}_{S_{2}}^{w_{2}}+\cdots+\tilde{A}_{S_{n}}^{w_{n}}= \\
\left\{\prod_{i=1}^{n} \mu_{\tilde{A}_{S_{i}}}^{w_{i}},\left[1-\prod_{i=1}^{n}\left(1-v_{\tilde{A}_{S_{i}}}^{2}\right)^{w_{i}}\right]^{1 / 2},\left[\prod_{i=1}^{n}\left(1-v_{\tilde{A}_{S_{i}}}^{2}\right)^{w_{i}}-\prod_{i=1}^{n}\left(1-v_{\tilde{A}_{S_{i}}}^{2}-\pi_{\tilde{A}_{S_{i}}}^{2}\right)^{w_{i}}\right]^{1 / 2}\right\},
\end{gathered}
$$

where $w_{i} \in[0,1] ; \sum_{i=1}^{n} w_{i}=1$.

Since the introduction of SFSs, several functions were proposed to defuzzify these sets for evaluation, prioritization, and ranking.

The score and accuracy functions as given by Gündoğdu and Kahraman (2019a)

$\operatorname{Score}\left(\tilde{A}_{s}\right)=\left(\mu_{\tilde{A}_{s}}-\pi_{\tilde{A}_{s}}\right)^{2}-\left(v_{\tilde{A}_{s}}-\pi_{\tilde{A}_{s}}\right)^{2}$, 
$\operatorname{Accuracy}\left(\tilde{A}_{S}\right)=\mu_{\tilde{A}_{s}}^{2}+v_{\tilde{A}_{s}}^{2}+\pi_{\tilde{A}_{s}}^{2}$

$\tilde{A}_{s}<\tilde{B}_{s} \quad$ iff $\operatorname{Score}\left(\tilde{A}_{s}\right)<\operatorname{Score}\left(\tilde{B}_{s}\right)$,

or $\operatorname{Score}\left(\tilde{A}_{s}\right)=\operatorname{Score}\left(\tilde{B}_{s}\right)$ and $\operatorname{Accuracy}\left(\tilde{A}_{s}\right)<\operatorname{Accuracy}\left(\tilde{B}_{s}\right)$.

Later Gündoğdu and Kahraman (2019b) proposed the following score function

$\operatorname{Score}\left(\tilde{A}_{s}\right)=\left(2 \mu_{\tilde{A}_{s}}-\pi_{\tilde{A}_{s}}\right)^{2}-\left(v_{\tilde{A}_{s}}-\pi_{\tilde{A}_{s}}\right)^{2}$.

Gündoğdu and Kahraman (2020a, 2020b) also proposed the following score functions respectively

$\operatorname{Score}\left(\tilde{A}_{s}\right)=\left(2 \mu_{\tilde{A}_{s}}\right)^{2}-v_{\tilde{A}_{s}}^{2}-\pi_{\tilde{A}_{s}}^{2} / 2$,

and $\operatorname{Score}\left(\tilde{A}_{s}\right)=\sqrt{\left|100 *\left[\left(3 \mu_{\tilde{A}_{s}}-\frac{\pi_{\widetilde{A}_{s}}}{2}\right)^{2}-\left(\frac{v_{\widetilde{A}_{s}}}{2}-\pi_{\tilde{A}_{s}}\right)^{2}\right]\right|}$.

The conjugate of an SFS is given by (Ashraf et al. 2019)

$$
\tilde{A}_{s}^{c}=\left(v_{\tilde{A}_{s}}, \mu_{\tilde{A}_{s}}, \pi_{\tilde{A}_{s}}\right) \text {. }
$$

The Euclidean distance is given by

$$
\operatorname{dis}_{E}\left(\tilde{A}_{s}, \tilde{B}_{S}\right)=\sqrt{\left(\mu_{\tilde{A}_{s}}-\mu_{\tilde{B}_{S}}\right)^{2}+\left(v_{\tilde{A}_{s}}-v_{\tilde{B}_{S}}\right)^{2}+\left(\pi_{\tilde{A}_{s}}-\pi_{\tilde{B}_{S}}\right)^{2}} \text {. }
$$

The spherical distance is given by

$\operatorname{dis}_{S p}\left(\tilde{A}_{s}, \tilde{B}_{S}\right)=\frac{2}{\pi}\left(\arccos \left(\mu_{\tilde{A}_{s}} \mu_{\tilde{B}_{S}}+v_{\tilde{A}_{S}} v_{\tilde{B}_{S}}+\pi_{\tilde{A}_{s}} \pi_{\tilde{B}_{S}}\right)\right)$.

The Xu and Zhang's distance is given by

$\operatorname{dis}_{X Z}\left(\tilde{A}_{s}, \tilde{B}_{S}\right)=\frac{1}{2}\left|\left(\mu_{\tilde{A}_{s}}-\mu_{\tilde{B}_{s}}\right)^{2}+\left(v_{\tilde{A}_{s}}-v_{\tilde{B}_{S}}\right)^{2}+\left(\pi_{\tilde{A}_{s}}-\pi_{\tilde{B}_{S}}\right)^{2}\right|$.

\subsection{The conventional TOPSIS and VIKOR}

Both TOPSIS and VIKOR are distance-based methods. The first two steps are common in both techniques.

Step 1: Formation of the decision matrix $\mathbf{D}$ that contains $n$ alternatives and $m$ criteria,

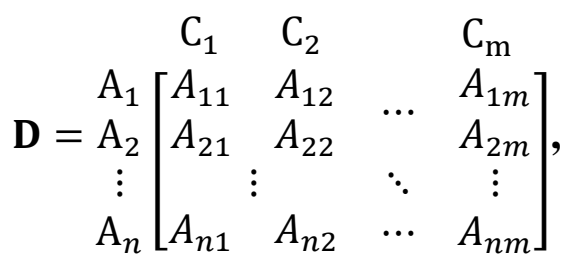

where $A_{i j}$ is the rating of the $i^{\text {th }}$ alternative for the $j^{\text {th }}$ criterion.

Step 2: Determination of the weights of the criteria.

The decision-makers assign a set of weights for the criteria since the criteria are not equally important,

$$
\mathbf{W}=\left[\begin{array}{llll}
w_{1} & w_{2} & \cdots & w_{m}
\end{array}\right] .
$$


The weights of the criteria satisfy $w_{j}>0$ and $\sum_{j=1}^{m} w_{j}=1$.

\section{First, the TOPSIS steps are continued as follows.}

Step T3: Normalization of the decision matrix.

Since the criteria have different dimensions, the normalization process is necessary to transform the dimensional criteria to non-dimensional to allow the comparison process.

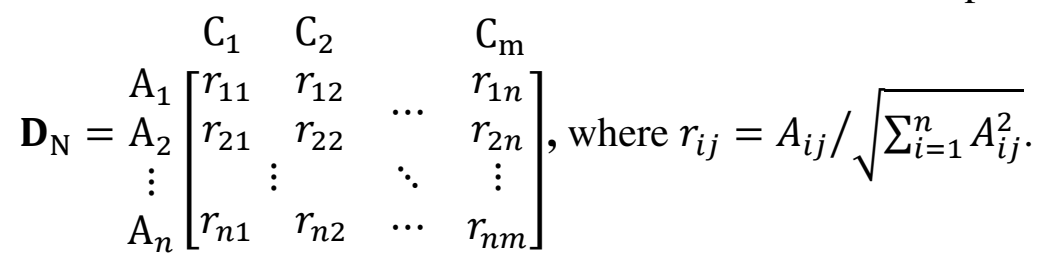

Step T4: Formation of the weighted normalized decision matrix.

Each criterion is multiplied by its assigned weight

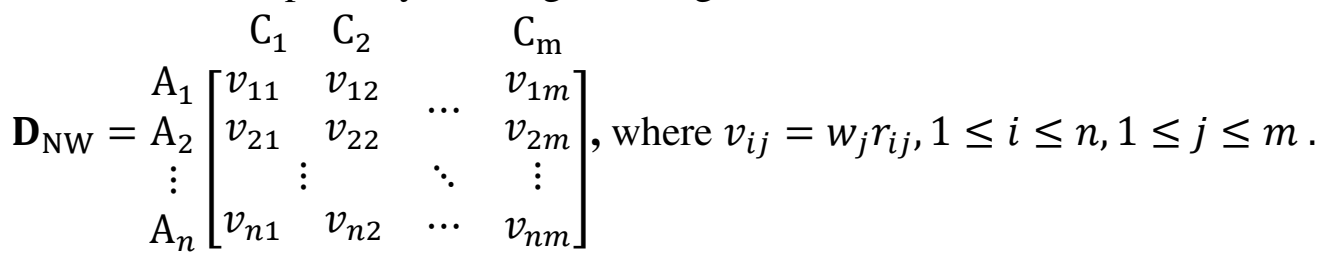

Step T5: Determination of both the positive and negative ideal solutions.

$$
\begin{aligned}
& \boldsymbol{v}^{+}=\left\{\left(\max _{i} v_{i j} \mid j \in \mathrm{C}_{\mathrm{b}}\right),\left(\min _{i} v_{i j} \mid j \in \mathrm{C}_{\mathrm{c}}\right) \mid j=1,2, \ldots m\right\}=\left(v_{1}^{+}, v_{2}^{+}, \ldots v_{m}^{+}\right), \\
& \boldsymbol{v}^{-}=\left\{\left(\min _{i} v_{i j} \mid j \in \mathrm{C}_{\mathrm{b}}\right),\left(\max _{\boldsymbol{i}} \boldsymbol{v}_{i j} \mid j \in \mathrm{C}_{\mathrm{c}}\right) \mid j=1,2, \ldots m\right\}=\left(v_{1}^{-}, v_{2}^{-}, \ldots v_{m}^{-}\right),
\end{aligned}
$$

where $\mathrm{C}_{\mathrm{b}}$ and $\mathrm{C}_{\mathrm{c}}$ are the benefit criteria and the cost criteria, respectively.

Step T6: Calculation of the separation measures.

The distance between each alternative and the positive and negative ideal solutions is calculated using the Euclidean distance

$$
S_{i}^{+}=\sqrt{\sum_{j=1}^{m}\left(v_{i j}-v^{+}\right)^{2}} \text {, and } S_{i}^{-}=\sqrt{\sum_{j=1}^{m}\left(v_{i j}-v^{-}\right)^{2}}, j=1,2, \ldots m .
$$

Step T7: Calculation of the relative degree of closeness to the ideal solution.

$$
R_{i}=\frac{S_{i}^{-}}{S_{i}^{+}+S_{i}^{-}}, \quad i=1,2, \ldots n .
$$

Step T8: Formation of the preference order.

The alternatives are ranked in descending order according to the relative degree of closeness.

\section{Second, the VIKOR steps are continued as follows.}

Step V3: Determination of both the positive and negative ideal solutions.

$$
\begin{aligned}
& \mathbf{A}^{+}=\left\{\left(\max _{i} \mathrm{~A}_{i j} \mid j \in \mathrm{C}_{\mathrm{b}}\right),\left(\min _{\boldsymbol{i}} \mathrm{A}_{\mathrm{ij}} \mid j \in \mathrm{C}_{\mathrm{c}}\right) \mid j=1,2, \ldots m\right\}=\left(\mathrm{A}_{1}^{+}, \mathrm{A}_{2}^{+}, \ldots \mathrm{A}_{\mathrm{m}}^{+}\right), \\
& \mathbf{A}^{-}=\left\{\left(\min _{\boldsymbol{i}} \mathrm{A}_{\mathrm{ij}} \mid j \in \mathrm{C}_{\mathrm{b}}\right),\left(\max _{\boldsymbol{i}} \mathrm{A}_{\mathrm{ij}} \mid j \in \mathrm{C}_{\mathrm{c}}\right) \mid j=1,2, \ldots m\right\}=\left(\mathrm{A}_{1}^{-}, \mathrm{A}_{2}^{-}, \ldots \mathrm{A}_{\mathrm{m}}^{-}\right) .
\end{aligned}
$$

Step V4: Calculation of the separation measures. 
The distance between each alternative and the positive and negative ideal solutions is calculated using the $L_{P}$ metric $\left(L_{P, i}=\left\{\sum_{j=1}^{m}\left[w_{j}\left(\mathrm{~A}_{j}^{+}-\mathrm{A}_{i j}\right) /\left(\mathrm{A}_{j}^{+}-\mathrm{A}_{j}^{-}\right)^{P}\right]\right\}^{1 / P}, 1 \leq P \leq \infty\right)$ to compute the group utility and the individual regret of the opponent (Ren et al. 2017).

$$
S_{i}=L_{1, i}=\sum_{j=1}^{m} w_{j}\left(\mathrm{~A}_{j}^{+}-\mathrm{A}_{i j}\right) /\left(\mathrm{A}_{j}^{+}-\mathrm{A}_{j}^{-}\right) \text {, and } R_{i}=L_{\infty, i}=\max _{j}\left[w_{j}\left(\mathrm{~A}_{j}^{+}-\mathrm{A}_{i j}\right) /\left(\mathrm{A}_{j}^{+}-\mathrm{A}_{j}^{-}\right)\right] \text {, }
$$

where $w_{j}$ is the weight of the $j^{\text {th }}$ criteria, $S_{i}$ is the utility measure, and $R_{i}$ is the regret measure.

Step V5: Determination of $S^{+}, S^{-}, R^{+}$, and $R^{-}$.

$S^{+}=\min _{i} S_{i}$ (the maximum group utility), $S^{-}=\max _{i} S_{i}$ (the minimum group utility),

$R^{+}=\min _{i} R_{i}$ (the minimum individual regret of the opponent),

and $R^{-}=\max _{i} R_{i}$ (the maximum individual regret of the opponent).

Step V6: Calculation of the index $Q_{i}$.

$$
Q_{i}=\gamma\left(S_{i}-S^{+}\right) /\left(S^{-}-S^{+}\right)+(1-\gamma)\left(R_{i}-R^{+}\right) /\left(R^{-}-R^{+}\right),
$$

where $\gamma \in[0,1]$ is the weight of the "the maximum group utility" strategy and $(1-\gamma)$ is the weight of "the individual regret".

Step V7: Proposition of a compromise solution.

Form three ranking lists of the alternatives by sorting the values of $S, R$ and $Q$ in ascending order. The alternative with minimum $Q$ is the best choice, $\mathrm{A}^{(1)}$, under the following conditions.

First condition: Acceptable advantage $Q\left(\mathrm{~A}^{(2)}\right)-Q\left(\mathrm{~A}^{(1)}\right) \geq 1 /(n-1)$, where $\mathrm{A}^{(2)}$ is the $2^{\text {nd }}$ alternative in the $Q$ ranking list.

If this condition is not satisfied, then $\mathrm{A}^{(1)}, \mathrm{A}^{(2)}, \cdots, \mathrm{A}^{(r)}$ are the compromised solutions with $\mathrm{A}^{(r)}$ satisfying $Q\left(\mathrm{~A}^{(r)}\right)-Q\left(\mathrm{~A}^{(1)}\right)<1 /(n-1)$.

\section{Second condition: Acceptable stability in decision making}

The alternative $\mathrm{A}^{(1)}$ is ranked $1^{\text {st }}$ in the $S$ and/or $R$ ranking lists.

If this condition is not satisfied, then $\mathrm{A}^{(1)}$ and $\mathrm{A}^{(2)}$ are the compromised solutions.

\section{The proposed techniques}

\subsection{The SF-TOPSIS and SF-VIKOR}

Due to the recent development of SFSs, the proposed new defuzzification formulas may affect the rankings since it has not been widely researched (Gündoğdu and Kahraman 2020b). Since TOPSIS and VIKOR are based mainly on the distance from the best and worst solutions, this requires an early ranking and so early defuzzification is inevitable to identify these two solutions. Consequently, these techniques are strongly affected by the used defuzzification formula. Accordingly, it is preferable to delay the defuzzification, as possible, and restrict it to the final ranking to minimize its effect. 
As known, the distance between the best and worst solutions is the largest distance among the available ratings. Yet, since SFSs are defined in 3D, this basic concept might not be realized in some cases with some distance formulas. Up till now Gündoğdu and Kahraman (2019a, 2019b, 2020a, 2020b) proposed the score functions (9), (11), (12), and (13) to evaluate and rank SFSs. For example, Consider the SFSs $\tilde{S}_{1}=(0.73,0.30,0.31), \tilde{S}_{2}=(0.71,0.54,0.45)$, and $\tilde{S}_{3}=(0.81,0.46,0.26)$. The rank of these SFSs is $\tilde{S}_{3}, \tilde{S}_{1}$, and $\tilde{S}_{2}$ by the four score functions. Then, $\tilde{S}_{3}$ is the best solution and $\tilde{S}_{2}$ is the worst solution. It is expected that the distance between $\tilde{S}_{3}$ and $\tilde{S}_{2}$ should be the largest. However, using the Euclidean distance (15), the distances are: $\operatorname{dis}_{E}\left(\tilde{S}_{1}, \tilde{S}_{2}\right)=$ 0.2786, $\operatorname{dis}_{E}\left(\tilde{S}_{1}, \tilde{S}_{3}\right)=0.1857$, and $\operatorname{dis}_{E}\left(\tilde{S}_{2}, \tilde{S}_{3}\right)=0.2291$. Hence, the distance between $\tilde{S}_{3}$ and $\tilde{S}_{2}$ is not the largest. When using the spherical distance (16), the distances are: $\operatorname{dis}_{S p}\left(\tilde{S}_{1}, \tilde{S}_{2}\right)=0.3882, \operatorname{dis}_{S p}\left(\tilde{S}_{1}, \tilde{S}_{3}\right)=0.3990$, and $\operatorname{dis}_{S p}\left(\tilde{S}_{2}, \tilde{S}_{3}\right)=0.2207$. Here the distance between the reference points is the smallest. Xu and Zhang's distance gives $\operatorname{dis}_{X Z}\left(\tilde{S}_{1}, \tilde{S}_{2}\right)=0.1687, \operatorname{dis}_{X Z}\left(\tilde{S}_{1}, \tilde{S}_{3}\right)=0.1367$, and $\operatorname{dis}_{X Z}\left(\tilde{S}_{2}, \tilde{S}_{3}\right)=0.1835$. Then, $\mathrm{Xu}$ and Zhang's distance is the only distance formula that preserves the maximum distance between the reference points.

When an SFS is used to express the performance of an alternative for a criterion, this SFS can be viewed in itself as a measure of proximity to the aspired level. As the support " $\mu$ " increases and both the objection " $v$ " and hesitation " $\pi$ " decrease, the performance of an alternative for a criterion approaches the aspired level and its efficiency increases. In contrast, as the support " $\mu$ " decreases and both the objection " $v "$ and hesitation " $\pi$ " increase, the performance of an alternative for a criterion approaches the ineffectual level and its deficiency increases. Therefore, efficiency measures the ability of an alternative to function properly and meet the DMs' expectations. As the efficiency increases, the DMs' level of satisfaction increases. Conversely, the deficiency measures the incompetence of an alternative for a criterion. As the deficiency increases, the DMs' level of satisfaction decreases. In the proposed SF techniques the efficiency and deficiency measures replace the separation measures, i.e. distance from the positive and the negative ideal solutions.

Similar to the conventional methods, the basic step is the same. The ratings of the experts regarding the performance of the alternatives for the criteria and the importance of the criteria are aggregated using the SWAM operator (7) to get the decision matrix and the weighting matrix. If the weights of the DMs are expressed by SFSs, then SFmultiplication (4) and SF-addition (3) are utilized.

In the context of SFSs, another two steps, after the formation of the decision matrix and weighting matrix, are common between the two techniques. We first form the weighted decision matrix, and then the total efficiency measure of each alternative is calculated by adding its performance ratings for the whole criteria. After that, each technique is completed separately. 
For the proposed SF-TOPSIS, while the efficiency is used to measure the proximity to the positive ideal solution, the deficiency is used to measure the proximity to the negative ideal solution. The total deficiency measure for each alternative is calculated by adding the performance ratings in the conjugate of the weighted decision matrix for the whole criteria. Formula (11) is utilized to defuzzify the efficiency and deficiency measures. After that, the relative efficiency is computed by dividing the total efficiency measure by the sum of both the total efficiency and total deficiency measures. The alternative with the highest relative efficiency is the best.

In the proposed SF-VIKOR the concepts of the conventional VIKOR are reversed. In the conventional VIKOR, the closeness of an alternative to the positive ideal solution using the $L_{P}$ metric to formulate the group utility and the individual regret is used. Herein, the efficiency is used as a measure of the group utility. As previously mentioned, the DMs' satisfaction increases as the efficiency increases. Thus, the regret measure is replaced by the satisfaction measure. Hence, the minimum satisfaction represents the maximum regret. Therefore, instead of minimizing the sum of the individual regret, we maximize the sum of the individual satisfaction. Similarly, instead of minimizing the maximum regret, we maximize the minimum satisfaction.

After calculating the total efficiency for measuring the utility, the weighted decision matrix is defuzzified using (11) to find the minimum satisfaction. Then, the maximum efficiency $\left(S^{+}=\max _{i} S_{i}\right)$, the minimum efficiency $\left(S^{-}=\min _{i} S_{i}\right)$, the maximum satisfaction $\left(R^{+}=\max _{i} R_{i}\right)$, and the minimum satisfaction $\left(R^{-}=\min _{i} R_{i}\right)$ are determined. Accordingly, the " $S$ " and " $R$ " lists are ranked in descending order. Finally, the index " $Q$ " for each alternative is determined by computing its closeness to the maximum values. The alternative with the smallest index " $Q$ " is the best.

The steps for the proposed SF-TOPSIS and the SF-VIKOR can be summarized as follows.

For an MCDM problem with a set of $n$ alternatives $A=\left\{A_{1}, A_{2}, \ldots, A_{n}\right\}$, a set of $m$ criteria $\mathrm{C}=\left\{\mathrm{C}_{1}, \mathrm{C}_{2}, \ldots, \mathrm{C}_{m}\right\}$, and a set of $k$ decision-makers $\mathrm{D}=\left\{\mathrm{D}_{1}, \mathrm{D}_{2}, \ldots, \mathrm{D}_{k}\right\}$ whose weights are $\left\{\omega_{1}, \omega_{2}, \ldots, \omega_{k}\right\}$.

Step 1: Formation of the weighting matrices, the aggregated weighting matrix, the decision matrices, and the aggregated decision matrix.

The weighting matrix and the decision matrix of the $p^{\text {th }} \mathrm{DM}$ are given by

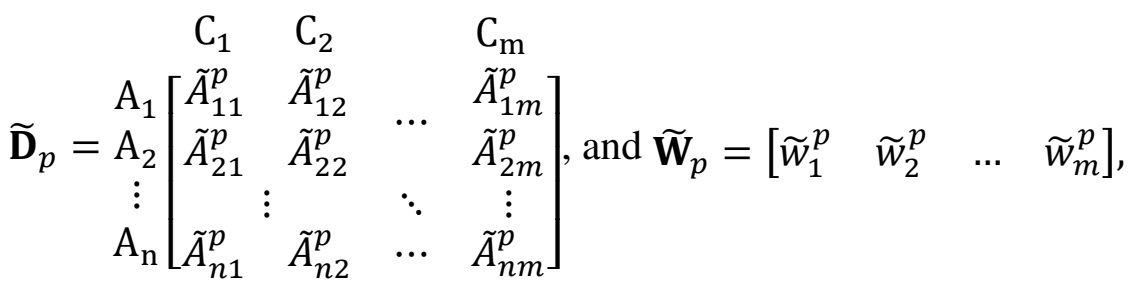


where $\tilde{A}_{i j}^{p}$ is the $p^{t h}$ DM's rating of the performance of $i^{t h}$ alternative for the $j^{\text {th }}$ criterion, and $\widetilde{w}_{j}^{p}$ is his evaluation of the importance of the $j^{\text {th }}$ criterion.

The average decision matrix and the average weighting matrix are computed using (3) and (5), or the SWAM operator (7) directly, as follows

$$
\widetilde{\mathbf{D}}_{a}=\left[\tilde{d}_{i j}\right]=\left[\begin{array}{c}
k \\
\bigoplus \\
p=1
\end{array} \omega_{p} \odot \tilde{A}_{i j}^{p}\right] \text {, and } \widetilde{\mathbf{W}}_{a}=\left[\widetilde{w}_{j}\right]=\left[\begin{array}{c}
k \\
\left.\underset{p=1}{\oplus} \omega_{p} \odot \widetilde{w}_{j}^{p}\right] .
\end{array}\right.
$$

Step 2: Formation of the weighted decision matrix using (4).

$$
\widetilde{\mathbf{D}}_{w}=\left[\tilde{\delta}_{i j}\right] \text {, where } \tilde{\delta}_{i j}=\left[\widetilde{w}_{j} \otimes \tilde{d}_{i j}\right] \text {. }
$$

Step 3: Calculate the measure of total efficiency

$$
\tilde{\mathbf{S}}=\left[\tilde{S}_{i}\right]=\bigoplus_{j=1}^{m} \tilde{\delta}_{i j}
$$

The previous three steps are common in the proposed SF-TOPSIS and SF-VIKOR. Thereafter, the steps of each technique are given separately.

First, the rest of the steps of the proposed SF-TOPSIS can be given as follows.

Step T4: Formation of the conjugate weighted decision matrix using (14).

$$
\widetilde{\mathbf{D}}_{c}=\left[\tilde{\delta}_{i j}^{c}\right]
$$

Step T5: Calculate the measure of total deficiency

$$
\widetilde{\mathbf{R}}=\left[\tilde{R}_{i}\right]={\underset{j=1}{m}}_{j=1}^{m} \tilde{\delta}_{i j}^{c}
$$

Step T6: Deffuzify $\tilde{S}_{i}$ and the $\tilde{R}_{i}$ using (11).

$$
\begin{aligned}
S_{i} & =\operatorname{Score}\left(\tilde{S}_{i}\right)=\left(2 \mu_{\tilde{S}_{i}}-\pi_{\tilde{S}_{i}}\right)^{2}-\left(v_{\tilde{S}_{i}}-\pi_{\tilde{S}_{i}}\right)^{2}, \\
\text { and } R_{i} & =\operatorname{Score}\left(\tilde{R}_{i}\right)=\left(2 \mu_{\tilde{R}_{i}}-\pi_{\tilde{R}_{i}}\right)^{2}-\left(v_{\tilde{R}_{i}}-\pi_{\tilde{R}_{i}}\right)^{2} .
\end{aligned}
$$

Step T7: Calculate the relative efficiency.

$$
R E_{i}=S_{i} /\left(S_{i}+R_{i}\right)
$$

The alternatives are ranked in descending order according to the relative efficiency. The best alternative is the one with the maximum relative efficiency.

The flowchart of the proposed SF-TOPSIS is presented in Fig. 1 to illustrate the method.

Fig. 1 The flowchart of the proposed SF-TOPSIS

Second, the rest of the steps of the proposed SF-VIKOR are given as follows.

Step V4: Defuzzify $\widetilde{\mathbf{D}}_{w}$ and $\widetilde{\mathbf{S}}$ using (11). 


$$
\begin{aligned}
& \mathbf{D}_{w}=\left[\delta_{i j}\right] \text {, and } \boldsymbol{S}=\left[S_{i}\right] \text {, where } \\
& \qquad \begin{array}{l}
S_{i}=\operatorname{Score}\left(\tilde{S}_{i}\right)=\left(2 \mu_{\tilde{S}_{i}}-\pi_{\tilde{S}_{i}}\right)^{2}-\left(v_{\tilde{S}_{i}}-\pi_{\tilde{S}_{i}}\right)^{2}, \\
\text { and } \delta_{i j}=\operatorname{Score}\left(\tilde{\delta}_{i j}\right)=\left(2 \mu_{\widetilde{\delta}_{i}}-\pi_{\widetilde{\delta}_{i}}\right)^{2}-\left(v_{\widetilde{\delta}_{i}}-\pi_{\widetilde{\delta}_{i}}\right)^{2} .
\end{array}
\end{aligned}
$$

Step V5: Find the minimum satisfaction (i.e. maximum regret).

$$
\boldsymbol{R}=\left[R_{i}\right]=\left[\min _{j} \delta_{i j}\right]
$$

Step V6: Determine $S^{+}, S^{-}, R^{+}$, and $R^{-}$.

The maximum group utility, the maximum efficiency, $S^{+}=\max _{i} S_{i}$.

The minimum group utility, the minimum efficiency, $S^{-}=\min _{i} S_{i}$.

The maximum individual satisfaction, $R^{+}=\max _{i} R_{i}$.

The minimum individual satisfaction, $R^{-}=\min _{i} R_{i}$.

Step V7: Calculate the index $Q_{i}$.

$Q_{i}=\gamma\left(S^{+}-S_{i}\right) /\left(S^{+}-S^{-}\right)+(1-\gamma)\left(R^{+}-R_{i}\right) /\left(R^{+}-R^{-}\right)$,

where $\gamma$ as previously mentioned is the weight of "the maximum group utility" strategy.

Step V8: Rank the alternatives and find a compromise solution.

Three ranking lists are formed according to the $S, R$, and $Q$ values. The alternatives in the $S$ and $R$ lists are arranged in descending order. Meanwhile, they are ranked in ascending order in the $Q$ list. The alternative with minimum $Q$ is the best choice under the same previously mentioned conditions in the conventional VIKOR.

The flowchart of the proposed SF-VIKOR is presented in Fig. 2 to demonstrate the method.

Fig. 2 The flowchart of the proposed SF-VIKOR

\subsection{Data transformation}

In this subsection, three types of data are transformed to SFSs, crisp values, type 1 triangular fuzzy numbers (TFNs), and linguistic variables.

\subsubsection{Transforming crisp values to SFSs}

To transform crisp values to SFSs, we have two cases. In the first case, there is an ultimate value, i.e. a required value to be attained for a criterion. In the second case, the ratings will be taken relative to each other.

In the first case, the crisp rating of the $i^{\text {th }}$ alternative for the $j^{\text {th }}$ criterion $\mathrm{A}_{\mathrm{ij}}$, is expressed as an SFS as follows.

$$
\begin{gathered}
\tilde{A}_{i j}=\left(\mu_{i j}, v_{i j}, \pi_{i j}\right) \text {, where } \\
\mu_{i j}=\text { crisp value } / \text { ultimte value }=\mathrm{A}_{\mathrm{ij}} / U_{j}, v_{i j}=1-\mu_{i j}, \text { and } \pi_{i j}=0 .
\end{gathered}
$$


Here, $\mu_{i j}$ is the degree of satisfaction at the performance of the alternative. It represents the extent to which an alternative achieves the desired performance. Meanwhile, $v_{i j}$ is the degree of dissatisfaction at the alternative as long as its performance didn't reach the desired level. Since $A_{i j}$ is a crisp value, it is strictly determined and there is no hesitation, i.e. the hesitation degree is zero.

In the second case, the crisp value is expressed as an SFS similar to the above case, but with replacing the ultimate value with the maximum available rating of the alternatives for a criterion as follows.

$$
\begin{gathered}
\tilde{A}_{\mathrm{ij}}=\left(\mu_{i j}, v_{i j}, \pi_{i j}\right) \text {, where } \\
\mu_{i j}=\text { crisp value } / \text { maximum rating }=\mathrm{A}_{\mathrm{ij}} / \max _{i} \mathrm{~A}_{\mathrm{ij}}, v_{i j}=1-\mu_{i j} \text {, and } \pi_{i j}=0 .
\end{gathered}
$$

\subsubsection{Transforming triangular fuzzy numbers to SFSS}

To transform triangular fuzzy numbers (TFNs), represented by the lower, middle, and upper values $\left(l_{i j}, m_{i j}, u_{i j}\right)$ to SFSs, the TFNs must be in the normalized form, i.e. in the interval $[0,1]$. The maximum upper value in the performance of the alternatives for the criteria $\left(\max _{i} u_{i j}\right)$ is set as the ultimate value. The degree of satisfaction $\mu_{i j}$ in the SFS $\widetilde{\mathrm{A}}_{\mathrm{ij}}$ is calculated by dividing the middle value of the TFN $\left(m_{i j}\right)$ by the maximum upper-value $\left(\max _{i} u_{i j}\right)$. This is an indicator of the effectiveness of an alternative regarding a criterion. As the middle- value changes between a lower and an upper value, the degree of hesitation is determined by taking the difference between the upper and lower values of the TFN. Then the SFS is given as follows.

$$
\begin{gathered}
\widetilde{\mathrm{A}}_{\mathrm{ij}}=\left(\mu_{i j}, v_{i j}, \pi_{i j}\right) \text {, where } \\
\mu_{i j}=m_{i j} / \max _{i} u_{i j}, \pi_{i j}=u_{i j}-l_{i j}, \text { and } v_{i j}=1-\left(\mu_{i j}+\pi_{i j}\right),
\end{gathered}
$$

under the condition $m_{i j} \leq \sqrt{\left(\max _{i} u_{i j}\right)^{2}\left(1-\left(u_{i j}-l_{i j}\right)^{2}\right)}$ to ensure that the transformed SFS satisfies condition (2).

\subsubsection{Transforming linguistic variables to SFSs}

The linguistic variables can be defined on a five-level, seven-level, or nine-level scales using SFSs as shown in Table 1.

Table 1. Linguistic variables as SFSs with different scales

\begin{tabular}{llllll}
\hline Linguistic terms & SFS (5 scale) & Linguistic terms & SFS (7 scale) & Linguistic terms & SFS (9 scale) \\
\hline Very Good & $(0.9,0.1,0.1)$ & Extremely good & $(0.9,0.1,0.1)$ & Superior & $(0.9,0.1,0.1)$ \\
Good & $(0.7,0.3,0.3)$ & Very good & $(0.8,0.2,0.2)$ & Extremely good & $(0.8,0.2,0.2)$ \\
Fair & $(0.5,0.5,0.5)$ & Good & $(0.7,0.3,0.3)$ & Very good & $(0.7,0.3,0.3)$ \\
Poor & $(0.3,0.7,0.3)$ & Fair & $(0.5,0.5,0.5)$ & Good & $(0.6,0.4,0.4)$ \\
Very Poor & $(0.1,0.9,0.1)$ & Poor & $(0.3,0.7,0.3)$ & Fair & $(0.5,0.5,0.5)$ \\
& & Very poor & $(0.2,0.8,0.2)$ & Poor & $(0.6,0.4,0.4)$ \\
& & Extremely poor & $(0.1,0.9,0.1)$ & Very poor & $(0.7,0.3,0.3)$ \\
& & & Extremely poor & $(0.2,0.8,0.2)$ \\
& & & Inferior & $(0.1,0.9,0.1)$ \\
\hline
\end{tabular}




\section{Applications}

Two practical examples are solved in this section to demonstrate the performance of the proposed techniques and to illustrate their applicability and validity. The first example is adopted from Gündoğdu and Kahraman (2019b) to handle a warehouse location selection problem in which both the weights of the criteria and the performance of the alternatives for the chosen criteria are SFSs.

The second example is adopted from Gim and Kim (2014) to evaluate hydrogen storage systems (HSSs) for automobiles in which the weights of the criteria are fuzzy while the performance of the alternatives for the evaluation criteria is crisp and linguistic. The data might have changed nowadays due to technological development. However, the main aim of presenting this example is to handle different types of data (crisp, linguistic, fuzzy) arising from HSSs problems and to introduce SFSs in this domain. Thus, provide decision- makers with a reliable and robust framework that makes them free to express their degree of hesitation.

\subsection{Warehouse site selection problem}

Four sub-provinces in Konya (Turkey) $\left\{\mathrm{A}_{1}, \mathrm{~A}_{2}, \mathrm{~A}_{3}, \mathrm{~A}_{4}\right\}$ are evaluated for the selection of a facility warehouse location. Four criteria were determined based on a comprehensive literature review: infrastructure $\left(\mathrm{C}_{1}\right)$, markets $\left(\mathrm{C}_{2}\right)$, costs $\left(\mathrm{C}_{3}\right)$, and labour characteristics $\left(C_{4}\right)$. Three experienced engineers $\left\{D_{1}, D_{2}, D_{3}\right\}$ in supply chain and logistics management were chosen to assess the criteria and the alternatives' performance for these criteria. The DMs use SFSs in their assessments. Since the decision-makers have different levels of experience, they are assigned different weights $\{0.3,0.2,0.5\}$. The used nine-level scale is given as follows. Absolutely more importance (AMI), very high importance (VHI), high importance (HI), slightly more importance (SMI), equal importance (EI), slightly low importance (SLI), low importance (LI), very low importance (VLI), and absolutely low importance (ALI). The equivalent SFS are:

$(0.9,0.1,0.1),(0.8,0.2,0.2),(0.7,0.3,0.3),(0.6,0.4,0.4),(0.4,0.6,0.4),(0.3,0.7,0.3),(0.2,0.8,0.2)$, and $(0.1,0.9,0.1)$, respectively. The steps of the proposed methodology are given as follows.

Step 1: Formation of the weighting matrices, the aggregated weighting matrix, the decision matrices, and the aggregated decision matrix.

The assessment of the DMs for the criteria:

$$
\begin{aligned}
& \begin{array}{llllllll}
\mathrm{C}_{1} & \mathrm{C}_{2} & \mathrm{C}_{3} & \mathrm{C}_{4} & \mathrm{C}_{1} & \mathrm{C}_{2} & \mathrm{C}_{3} & \mathrm{C}_{4}
\end{array} \\
& \mathbf{W}_{\mathbf{1}}=\left[\begin{array}{lllll}
\mathrm{HI} & \mathrm{VHI} & \mathrm{HI} & \mathrm{SLI}
\end{array}\right], \quad \mathbf{W}_{\mathbf{2}}=\left[\begin{array}{llll}
\mathrm{EI} & \mathrm{AMI} & \mathrm{VHI} & \mathrm{LI}
\end{array}\right], \\
& \begin{array}{llll}
\mathrm{C}_{1} & \mathrm{C}_{2} & \mathrm{C}_{3} & \mathrm{C}_{4}
\end{array} \\
& \text { and } \mathbf{W}_{3}=\left[\begin{array}{llll}
E I & H I & V H I & E I
\end{array}\right] \text {. }
\end{aligned}
$$

Then, the aggregated weighting matrix using the SWAM operator (7) 


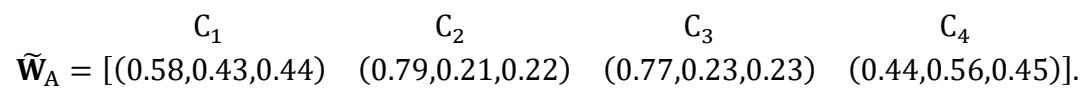

The evaluation of the DMs for the performance of the alternatives:

$$
\begin{aligned}
& \begin{array}{llllllll}
\mathrm{C}_{1} & \mathrm{C}_{2} & \mathrm{C}_{3} & \mathrm{C}_{4} & \mathrm{C}_{1} & \mathrm{C}_{2} & \mathrm{C}_{3} & \mathrm{C}_{4}
\end{array}
\end{aligned}
$$

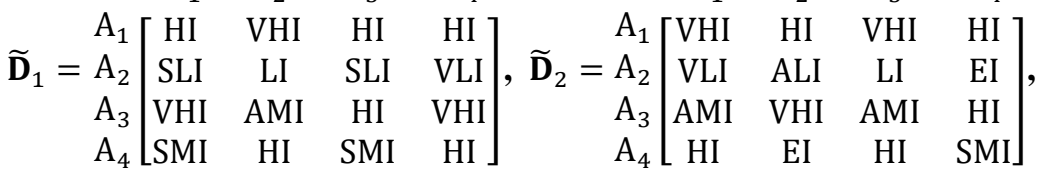

$$
\begin{aligned}
& \begin{array}{llll}
\mathrm{C}_{1} & \mathrm{C}_{2} & \mathrm{C}_{3} & \mathrm{C}_{4}
\end{array}
\end{aligned}
$$

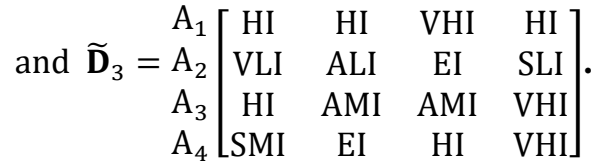

Then, the aggregated decision matrix using the SWAM operator (7)

$$
\begin{aligned}
& \begin{array}{llll}
\mathrm{C}_{1} & \mathrm{C}_{2} & \mathrm{C}_{3} & \mathrm{C}_{4}
\end{array} \\
& \widetilde{\mathbf{D}}_{a}=\left[\tilde{A}_{\mathrm{ij}}\right]=\begin{array}{r}
\mathrm{A}_{1} \\
\mathrm{~A}_{2} \\
\mathrm{~A}_{3}
\end{array}\left[\begin{array}{llll}
(0.72,0.28,0.28) & (0.74,0.27,0.27) & (0.77,0.23,0.23) & (0.70,0.30,0.30) \\
& \mathrm{A}_{4} \\
(0.28,0.73,0.29) & (0.19,0.83,0.19) & (0.44,0.56,0.45) & (0.38,0.63,0.39) \\
(0.62,0.38,0.38) & (0.58,0.43,0.44) & (0.67,0.33,0.33) & (0.74,0.26,0.28)
\end{array}\right] \text {. }
\end{aligned}
$$

Step 2: Formation of the weighted decision matrix using (4).

$$
\begin{aligned}
& \mathrm{C}_{1} \\
& \mathrm{C}_{2} \quad \mathrm{C}_{3} \\
& \mathrm{~A}_{1}\left[\begin{array}{llll}
(0.42,0.5,0.48) & (0.58,0.34,0.33) & (0.60,0.32,0.31) & (0.31,0.62,0.47)
\end{array}\right.
\end{aligned}
$$

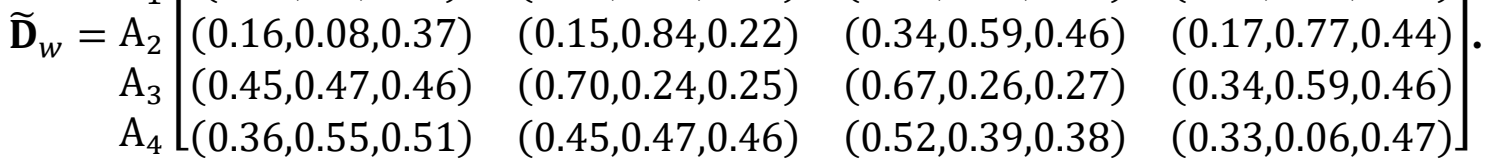

Step 3: Calculate the measure of efficiency

$$
\tilde{\boldsymbol{S}}_{i}=\left[\begin{array}{c}
(0.8263,0.0324,0.4422) \\
(0.4257,0.3040,0.6454) \\
(0.8957,0.0177,0.3387) \\
(0.7423,0.0608,0.5568)
\end{array}\right] .
$$

Using the proposed SF-TOPSIS the solution is accomplished as follows.

Step T4: Formation of the conjugate weighted decision matrix using (14).

$$
\begin{aligned}
& \begin{array}{cccc}
\mathrm{C}_{1} & \mathrm{C}_{2} & \mathrm{C}_{3} & \mathrm{C}_{4}
\end{array} \\
& \mathrm{~A}_{1}\left[\begin{array}{llll}
(0.50,0.42,0.48) & (0.34,0.58,0.33) & (0.32,0.60,0.31) & (0.62,0.31,0.47)
\end{array}\right]
\end{aligned}
$$

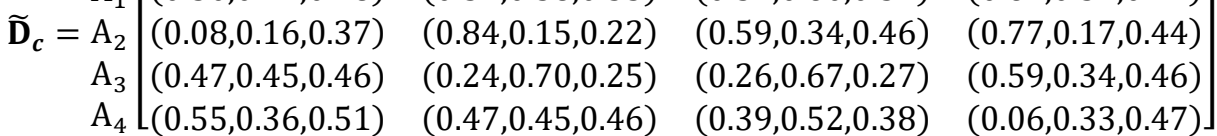

Step T5: Calculate the measure of deficiency

$$
\widetilde{\boldsymbol{R}}_{i}=\left[\begin{array}{l}
(0.7918,0.0447,0.4940) \\
(0.9858,0.0013,0.1537) \\
(0.7463,0.0732,0.5085) \\
(0.8407,0.0278,0.4698)
\end{array}\right] .
$$

Step T6: Deffuzify $\widetilde{\boldsymbol{S}}_{i}$ and the $\widetilde{\boldsymbol{R}}_{i}$ using (11). 


$$
\boldsymbol{S}_{i}=\left[\begin{array}{c}
1.2973 \\
-0.0741 \\
2.0072 \\
0.6149
\end{array}\right] \text {, and } \boldsymbol{R}_{i}=\left[\begin{array}{c}
0.9853 \\
3.2789 \\
0.7789 \\
1.2723
\end{array}\right] \text {. }
$$

Step T7: Calculate the relative efficiency.

$$
R E_{i}=S_{i} /\left(S_{i}+R_{i}\right)=\left[\begin{array}{c}
0.5684 \\
-0.0231 \\
0.7204 \\
0.3258
\end{array}\right] .
$$

Then, the ranking is $A_{3}>A_{1}>A_{4}>A_{2}$.

Using the proposed SF-VIKOR the solution is achieved as follows.

Step V4: Defuzzify $\widetilde{\mathbf{D}}_{w}$ and $\tilde{\boldsymbol{S}}_{i}$

$$
\begin{aligned}
& \begin{array}{lllll}
\mathrm{C}_{1} & \mathrm{C}_{2} & \mathrm{C}_{3} & \mathrm{C}_{4}
\end{array}
\end{aligned}
$$

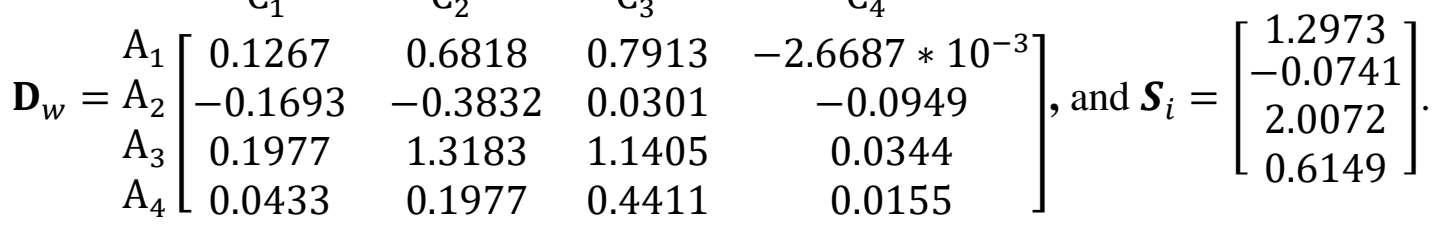

Step V5: Find the minimum efficiency.

$$
\boldsymbol{R}_{i}=\left[\begin{array}{c}
-2.6687 * 10^{-3} \\
-0.3832 \\
0.0344 \\
0.0155
\end{array}\right]
$$

Step V6: Determine $S^{+}, S^{-}, R^{+}$, and $R^{-}$.

$$
S^{+}=1.2973, S^{-}=-0.0741, R^{+}=0.0344, \text { and } R^{-}=-2.6687 * 10^{-3} \text {. }
$$

Step V7: Calculate the index $Q_{i}$.

$$
\boldsymbol{Q}_{i}=\left[\begin{array}{c}
0.2120 \\
1 \\
0 \\
0.3570
\end{array}\right]
$$

Step V8: Rank the alternatives and find a compromise solution.

The rank list of $S, R$ and $Q$ are given in Table 2.

\begin{tabular}{ccccc} 
Table 2 & \multicolumn{4}{c}{ The $S, R$ and $Q$ ranking list for the } \\
warehouse site selection problem
\end{tabular}

The condition of the acceptable stability is satisfied $A_{3}$ is ranked first by $S, R$ and $Q$. Meanwhile the acceptable advantage is not satisfied 


$$
Q\left(A_{3}\right)-Q\left(A_{1}\right)=0.2120 \geqq 1 / 3 .
$$

Therefore, $A_{3}$ and $A_{1}$ are the compromised solutions.

The $Q$ ranking list and the compromise solution remain unchanged for different values of $\gamma$, where $\gamma>0.5$ is used when voting by the majority rule, or $\gamma=0.5$ when voting by consensus, or $\gamma<0.5$ when voting with a veto.

The result obtained by the SF-VIKOR proposed by Gündoğdu and Kahraman (2019b) is: $A_{3}>A_{1}>A_{4}>A_{2}$ using score function (11) and utilizing the Euclidean distance (15), the spherical distance (16), and Xu and Zhang's distance (17). The result also remains the same using SF-TOPSIS employing $\mathrm{Xu}$ and Zhang distance (17). The results are summarized in Table 3.

It's worth noting that this example satisfies the basic notion in the reference point techniques. The distance between the best and worst solutions is the largest using the three employed distance measures. In consequence, the solution of the problem is ideal for comparison.

Table 3. Comparison of the alternatives with various methods for the warehouse site selection problem.

\begin{tabular}{lc}
\hline \multicolumn{1}{c}{ Method } & \multicolumn{1}{c}{ Ranking } \\
\hline SF-VIKOR (Euclidean distance) & $\mathrm{A}_{3}>\mathrm{A}_{1}>\mathrm{A}_{4}>\mathrm{A}_{2}$ \\
SF-VIKOR (Spherical distance) & $\mathrm{A}_{3}>\mathrm{A}_{1}>\mathrm{A}_{4}>\mathrm{A}_{2}$ \\
SF-VIKOR (Xu and Zhang distance) & $\mathrm{A}_{3}>\mathrm{A}_{1}>\mathrm{A}_{4}>\mathrm{A}_{2}$ \\
SF-TOPSIS (Xu and Zhang distance) & $\mathrm{A}_{3}>\mathrm{A}_{1}>\mathrm{A}_{4}>\mathrm{A}_{2}$ \\
Proposed SF-VIKOR & $\mathrm{A}_{3}>\mathrm{A}_{1}>\mathrm{A}_{4}>\mathrm{A}_{2}$ \\
Proposed SF-TOPSIS & $\mathrm{A}_{3}>\mathrm{A}_{1}>\mathrm{A}_{4}>\mathrm{A}_{2}$ \\
\hline
\end{tabular}

\subsection{Evaluation of hydrogen storage systems}

Hydrogen is a clean and reliable energy carrier, and it is one of the most promising players in the future energy system (Xu et al. 2019). Hydrogen storage is considered an essential technology for advancing hydrogen fuel cell vehicles. Despite hydrogen having the highest energy content per unit of weight (e.g. $33 \mathrm{kWh} / \mathrm{kg}$ for $\mathrm{H}_{2}$ compared to 12 $\mathrm{kWh} / \mathrm{kg}$ for gasoline), it has a low volume energy density (e.g. approximately1 $\mathrm{kWh} / \mathrm{L}$ for 700 bar $\mathrm{H}_{2}$ at $15^{\circ} \mathrm{C}$ compared to $9 \mathrm{kWh} / \mathrm{L}$ for gasoline) which makes it unfavourable to store and transport. Developing hydrogen storage systems (HSSs) that can store enough hydrogen (e.g. $4-10 \mathrm{~kg}$ to achieve a driving range of 300 to 500 miles) is a significant challenge (HSTTR 2017).

In this example, five hydrogen storage systems for automobiles are evaluated. These systems are 350 bar compressed gas hydrogen $\mathrm{CH}_{2} 350\left(\mathrm{~A}_{1}\right), 700$ bar compressed gas hydrogen $\mathrm{CH}_{2} 700\left(\mathrm{~A}_{2}\right)$, liquefied hydrogen $\mathrm{LH}_{2}\left(\mathrm{~A}_{3}\right)$, metal hydride $\mathrm{MH}\left(\mathrm{A}_{4}\right)$, and chemical hydride $\mathrm{CH}\left(\mathrm{A}_{5}\right)$. Five level-one criteria (storage efficiency, economy, durability and operability, safety, and infrastructure) are proposed. The first three criteria 
are divided into two sub-criteria. Then, eight level-two criteria are selected for the assessment process. The used criteria are defined as follows.

1) The weight efficiency $\left(C_{1}\right)$ : the net useful energy per maximum system mass.

2) The volume efficiency $\left(\mathrm{C}_{2}\right)$ : the net useful energy per maximum system volume.

3) The system cost $\left(\mathrm{C}_{3}\right)$ : the initial cost of the storage system.

4) The energy efficiency $\left(\mathrm{C}_{4}\right)$ : the net energy output divided by the net energy input for the HSS.

5) The cycle life $\left(\mathrm{C}_{5}\right)$ : durability and operability of the HSS.

6) The refuelling time $\left(\mathrm{C}_{6}\right)$ : the time to refuel $5 \mathrm{~kg}$ of hydrogen to hydrogen fuel cell vehicles.

7) Safety $\left(\mathrm{C}_{7}\right)$ : the extent to which the unit is safe from risk factors such as explosion or generation of harmful substances.

8) Infrastructure $\left(\mathrm{C}_{8}\right)$ : the current status or the future construction plan of the infrastructure for the HSS.

While the first three criteria are objective, the values of the rest of the criteria are not determined. Therefore, the linguistic terms (best, good, middle, bad, and worst) are used for evaluation. Gim and Kim (2014) used the bipolar method to convert the linguistic evaluation of the criteria into numerical values of $5,4,3,2$, and 1 . Hence, the performance data of the alternatives for the criteria is crisp. Then, this crisp quantitative hydrogen storage systems' data was normalized due to the difference in scale for each evaluation criteria.

Gim and Kim (2014) obtained the weights of the criteria using the fuzzy analytic hierarchy process since triangular fuzzy numbers were employed in evaluating the weights of the criteria to account for the uncertainty in human perception and judgement during the assessment process.

In this study, the data of the example are handled differently. The linguistic terms (best, good, middle, bad, and worst) are expressed by SFSs as given in Table 4.

Table 4. Linguistic terms for the HSSs

\begin{tabular}{lc}
\multicolumn{2}{l}{ problem expressed as SFS } \\
\hline Linguistic terms & SFS \\
\hline Best & $(0.9,0.1,0.1)$ \\
Good & $(0.7,0.3,0.3)$ \\
Middle & $(0.5,0.5,0.5)$ \\
Bad & $(0.3,0.7,0.3)$ \\
Worst & $(0.1,0.9,0.1)$ \\
\hline
\end{tabular}

In addition, instead of transforming the subjective evaluations to crisp values, the objective evaluations are transformed to SFSs. The main aim is to maintain the spherical fuzzy representation throughout the solution steps. The triangular fuzzy weights are also transformed to SFSs to attain the homogeneity of data. The original data of the problem (Gim and Kim 2014) are displayed in Table 5 with the ultimate values that could be attained (HSTTR 2017). Since the TFN are given for the level one criteria only of the 
hierarchy, the TFN of level 2 criteria are presumed from the resulting crisp values, e.g. $\mathrm{C}_{3}$ and $\mathrm{C}_{4}$ have equal weights. Before proceeding with the solution steps, the crisp values and the TFN are transformed to SFSs.

Table 5. The performance of the alternatives of the hydrogen storage systems for the criteria

\begin{tabular}{cccccccc}
\hline & $\mathrm{A}_{1}$ & $\mathrm{~A}_{2}$ & $\mathrm{~A}_{3}$ & $\mathrm{~A}_{4}$ & $\mathrm{~A}_{5}$ & $\begin{array}{c}\text { Ultimate } \\
\text { value }\end{array}$ & $\begin{array}{c}\text { Weights of the } \\
\text { criteria (TFN) }\end{array}$ \\
\hline $\mathrm{C}_{1}$ & 1.9 & 1.5 & 1.7 & 0.8 & 1.4 & 2.2 & $(0.164,0.234,0.332)$ \\
$\mathrm{C}_{2}$ & 0.5 & 0.8 & 1.2 & 0.6 & 1.0 & 1.7 & $(0.164,0.250,0.332)$ \\
$\mathrm{C}_{3}$ & 15 & 18 & 6 & 16 & 8 & 4 & $(0.123,0.181,0.261)$ \\
$\mathrm{C}_{4}$ & Best & Good & Bad & Middle & Worst & & $(0.123,0.181,0.261)$ \\
$\mathrm{C}_{5}$ & Best & Best & Good & Middle & Best & & $(0.110,0.162,0.246)$ \\
$\mathrm{C}_{6}$ & Best & Best & Good & Good & Middle & & $(0.110,0.162,0.246)$ \\
$\mathrm{C}_{7}$ & Middle & Middle & Good & Best & Good & & $(0.170,0.245,0.349)$ \\
$\mathrm{C}_{8}$ & Best & Best & Worst & Good & Middle & & $(0.123,0.178,0.261)$ \\
\hline
\end{tabular}

First, the crisp values are transformed to SFSs as follows.

$\tilde{A}_{\mathrm{ij}}=\left(\mu_{i j}, v_{i j}, \pi_{i j}\right)$, where

$\mu_{i j}=$ real value $/$ ultimte value,$v_{i j}=1-\mu_{i j}$, and $\pi_{i j}=0$.

Then, the decision matrix is given by

\begin{tabular}{|c|c|c|c|c|c|c|c|}
\hline $\mathrm{C}_{1}$ & $\mathrm{C}_{2}$ & $\mathrm{C}_{3}$ & $\mathrm{C}_{4}$ & $\mathrm{C}_{5}$ & $\mathrm{C}_{6}$ & $\mathrm{C}_{7}$ & $\begin{array}{c}\mathrm{C}_{8} \\
(0.9,0.1\end{array}$ \\
\hline & & & & & & & \\
\hline & & & & & & & \\
\hline & & & & & & & \\
\hline $36,0.64,0$ & $.35,0.65,0$ & $(0.25,0.75,0)$ & $(0.5,0.5,0.5)$ & $0.5,0.5,0.5)$ & $0.7,0.3,0.3)$ & $(0.9,0.1,0.1)$ & $(0.7,0.3,0$ \\
\hline & & & & & & & \\
\hline
\end{tabular}

Second, the triangular fuzzy weights $\left(l_{j}, m_{j}, u_{j}\right)$ are transformed to SFSs as follows.

$$
\widetilde{\mathrm{w}}_{\mathrm{j}}=\left(\mu_{j}, v_{j}, \pi_{j}\right), \text { where }
$$

$\mu_{j}=m_{j} / \max _{j} u_{j}, v_{j}=1-\left(\mu_{j}+\pi_{j}\right)$, and $\pi_{j}=u_{j}-l_{j}$.

Then, the weighting matrix is given by

$$
\widetilde{\mathbf{W}}=\left[\begin{array}{c}
(0.67,0.16,0.17) \\
(0.72,0.11,0.17) \\
(0.52,0.34,0.14) \\
(0.52,0.34,0.14) \\
(0.46,0.4,0.14) \\
(0.46,0.4,0.14) \\
(0.7,0.12,0.18) \\
(0.51,0.35,0.14)
\end{array}\right] .
$$

Then, the solution of SF-TOPSIS and SF-VIKOR proceeds as previously explained. The results are summarized in Table 6 and Table 7, respectively, where $\tilde{S}_{i}$ is the spherical fuzzy total efficiency, $S_{i}$ is its score, $\tilde{R}_{i}$ is the spherical fuzzy total deficiency, $R_{i}$ is its score, and $R E_{i}$ is the relative efficiency. 
The results of the SF-TOPSIS $\left(A_{1}>A_{2}>A_{3}>A_{5}>A_{4}\right)$ coincide completely with the results of Gim and Kim (2014). The best alternative of the SF-VIKOR is also $A_{1}$ for the different values of $\gamma$.

Table 6. Results of SF-TOPSIS for the evaluation of the hydrogen storage systems

\begin{tabular}{|c|c|c|c|c|c|c|}
\hline & $\tilde{S}_{i}$ & $S_{i}$ & $\widetilde{R}_{i}$ & $R_{i}$ & $R E_{i}$ & Rank \\
\hline $\mathrm{A}_{1}$ & $(0.8760,0.0013,0.3166)$ & 1.9610 & $(0.9617,0,0.1900)$ & 2.9687 & 0.3978 & 1 \\
\hline $\mathrm{A}_{2}$ & $(0.8452,0.0021,0.3678)$ & 1.6154 & $(0.9592,0,0.2052)$ & 2.8930 & 0.3583 & 2 \\
\hline $\mathrm{A}_{3}$ & $(0.8468,0.0020,0.3532)$ & 1.6731 & $(0.9869,0,0.1179)$ & 3.4307 & 0.3278 & 3 \\
\hline $\mathrm{A}_{4}$ & $(0.7993,0.0040,0.4611)$ & 1.0848 & $(0.9841,0,0.1498)$ & 3.2840 & 0.2483 & 5 \\
\hline $\mathrm{A}_{5}$ & $(0.8082,0.0041,0.4428)$ & 1.1851 & $(0.9879,0,0.1292)$ & 3.3933 & 0.2588 & 4 \\
\hline
\end{tabular}

Table 7. Results of SF-VIKOR for the evaluation of the hydrogen storage systems

\begin{tabular}{|c|c|c|c|c|c|c|}
\hline & $S_{i}$ & $\begin{array}{c}S_{i} \\
\text { Rank }\end{array}$ & $R_{i}$ & $\begin{array}{c}R_{i} \\
\text { Rank }\end{array}$ & $Q_{i}$ & $\begin{array}{c}Q_{i} \\
\text { Rank }\end{array}$ \\
\hline $\mathrm{A}_{1}$ & 1.9610 & 1 & -0.4152 & 1 & 0 & 1 \\
\hline $\mathrm{A}_{2}$ & 1.6154 & 3 & -0.4858 & 3 & 0.3517 & 2 \\
\hline $\mathrm{A}_{3}$ & 1.6731 & 2 & -0.6430 & 5 & 0.6643 & 4 \\
\hline $\mathrm{A}_{4}$ & 1.0848 & 5 & -0.4486 & 2 & 0.5734 & 3 \\
\hline $\mathrm{A}_{5}$ & 1.1851 & 4 & -0.6414 & 4 & 0.9392 & 5 \\
\hline
\end{tabular}

Yet, the $Q$ ranking list varies with different values of $\gamma$. This is due to the apparent variation in the performance of these alternatives for the evaluation criteria and its effect on individual satisfaction. For example, despite liquefied hydrogen $\left(\mathrm{A}_{3}\right)$ having high storage efficiency, it is the worst in the infrastructure. The $Q$ ranking is the same as that of the SF-TOPSIS for $\gamma=0.9$ and $\gamma=1$. The $Q$ ranking for different values of $\gamma \in[0,1]$ is given in Table 8 .

Table 8. $Q$ ranking for different values of $\gamma$ for the evaluation of HSSs

\begin{tabular}{|c|c|}
\hline$\gamma$ & $Q$ Rank \\
\hline 0 & $\mathrm{~A}_{1}>\mathrm{A}_{4}>\mathrm{A}_{2}>\mathrm{A}_{5}>\mathrm{A}_{3}$ \\
\hline 0.1 & $\mathrm{~A}_{1}>\mathrm{A}_{4}>\mathrm{A}_{2}>\mathrm{A}_{3}>\mathrm{A}_{5}$ \\
\hline 0.2 & $\mathrm{~A}_{1}>\mathrm{A}_{4}>\mathrm{A}_{2}>\mathrm{A}_{3}>\mathrm{A}_{5}$ \\
\hline 0.3 & $\mathrm{~A}_{1}>\mathrm{A}_{2}>\mathrm{A}_{4}>\mathrm{A}_{3}>\mathrm{A}_{5}$ \\
\hline 0.4 & $\mathrm{~A}_{1}>\mathrm{A}_{2}>\mathrm{A}_{4}>\mathrm{A}_{3}>\mathrm{A}_{5}$ \\
\hline 0.5 & $\mathrm{~A}_{1}>\mathrm{A}_{2}>\mathrm{A}_{4}>\mathrm{A}_{3}>\mathrm{A}_{5}$ \\
\hline 0.6 & $\mathrm{~A}_{1}>\mathrm{A}_{2}>\mathrm{A}_{3}>\mathrm{A}_{4}>\mathrm{A}_{5}$ \\
\hline 0.7 & $\mathrm{~A}_{1}>\mathrm{A}_{2}>\mathrm{A}_{3}>\mathrm{A}_{4}>\mathrm{A}_{5}$ \\
\hline 0.8 & $\mathrm{~A}_{1}>\mathrm{A}_{2}>\mathrm{A}_{3}>\mathrm{A}_{4}>\mathrm{A}_{5}$ \\
\hline 0.9 & $\mathrm{~A}_{1}>\mathrm{A}_{2}>\mathrm{A}_{3}>\mathrm{A}_{5}>\mathrm{A}_{4}$ \\
\hline 1 & $\mathrm{~A}_{1}>\mathrm{A}_{3}>\mathrm{A}_{2}>\mathrm{A}_{5}>\mathrm{A}_{4}$ \\
\hline
\end{tabular}

The rank corresponding to different values of the parameter $\gamma$ is given in Fig. 3 . As known in graphs, the length of the bar indicates its rank, the higher the bar the better the rank. Accordingly, instead of plotting the graph $Q$ versus $\gamma$, the graph is plotted $(1-Q)$ versus $\gamma$. 
Fig. 3 Change in rank for different values of $\gamma$ for the evaluation of HSSs

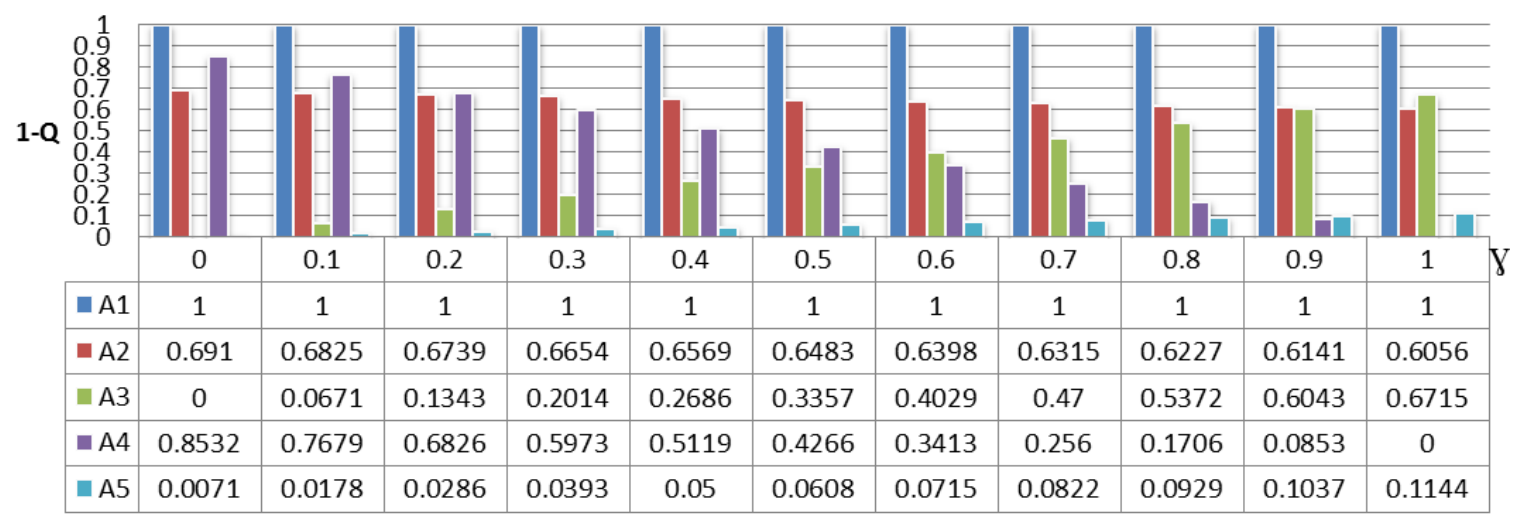

The performance of the proposed methodologies is compared with the performance of the SF-TOPSIS proposed by Gündoğdu and Kahraman (2019a) utilizing the Euclidean distance (17) with the score function (11) and Xu and Zhang distance with score function (11) for the evaluation of hydrogen storage systems. Herein, the distance between the best and worst solution is the largest. The results are summarized in Table 9 together with the results of the F-AHP of Gim and Kim (2014).

It should be pointed out that when utilizing the Euclidean distance (15) with the score function (9), the Spherical distance with the score functions (9) and (11), or Xu and Zhang distance (17) with score function (9), the SF-TOPSIS does not satisfy the basic notion of the reference point techniques, the distance between the best and worst solution is not the largest.

Table 9. Comparison of the alternatives with some methods for the evaluation of hydrogen storage systems.

\begin{tabular}{lc}
\multicolumn{1}{c}{ Method } & \multicolumn{1}{c}{ Ranking } \\
\hline SF-TOPSIS (Euclidean distance) & $\mathrm{A}_{1}>\mathrm{A}_{2}>\mathrm{A}_{3}>\mathrm{A}_{4}>\mathrm{A}_{5}$ \\
SF-TOPSIS (Xu and Zhang distance) & $\mathrm{A}_{1}>\mathrm{A}_{2}>\mathrm{A}_{3}>\mathrm{A}_{5}>\mathrm{A}_{4}$ \\
F-AHP (Gim and Kim 2014) & $\mathrm{A}_{1}>\mathrm{A}_{2}>\mathrm{A}_{3}>\mathrm{A}_{5}>\mathrm{A}_{4}$ \\
Proposed SF-VIKOR $(\gamma=0.9)$ & $\mathrm{A}_{1}>\mathrm{A}_{2}>\mathrm{A}_{3}>\mathrm{A}_{5}>\mathrm{A}_{4}$ \\
Proposed SF-TOPSIS & $\mathrm{A}_{1}>\mathrm{A}_{2}>\mathrm{A}_{3}>\mathrm{A}_{5}>\mathrm{A}_{4}$ \\
\hline
\end{tabular}

\section{Conclusion and discussion}

In this study, TOPSIS and VIKOR are implemented with a new perspective using the recently introduced SFSs. In the spherical fuzzy environment, two main issues might affect the ranking of the alternatives and cause incorrect results. First, the reference points might change with the utilized score function since score functions are newly developed and have not been widely researched. Second, the distance between the reference points might not be the largest among the available ratings. Hence, it is required to implement these methods in a way that reduces the effect of both defuzzification and distance formulas to overcome the defects and increase the robustness of SF-TOPSIS and SF-VIKOR. In the proposed SF-TOPSIS, the efficiency and deficiency measures replace the separation measures, i.e. distance from the best and worst solutions. In the proposed 
SF-VIKOR, the regret measure is replaced by the satisfaction measure, and the minimum satisfaction represents the maximum regret. Therefore, instead of minimizing the sum of the individual regret, we maximize the sum of the individual satisfaction. Similarly, instead of minimizing the maximum regret, we maximize the minimum satisfaction.

The proposed techniques form a robust platform for managers in the evaluation process due to the elimination of reference points, distance formulas, and minimizing the effect of defuzzification. They also enable the DMs to express their hesitation in the decision-making process by using a linguistic assessment scale based on SFSs. Thus, integrating the advantages of both PFSs and NFSs makes these techniques more powerful in handling vagueness and imprecision.

Moreover, the proposed methods form a flexible framework for managers. In most practical applications the data is not homogeneous. The data might be both subjective and objective. The objective data can be crisp and fuzzy. The fuzzy data also might not be the same type. Accordingly, it is important to develop SF-TOPSIS and SFVIKOR in the context of data merging due to the lack of techniques that can handle hybrid uncertainties properly within an evaluation system. Different types of data sets (crisp, linguistic variables, type 1 fuzzy sets) are transformed to SFSs to enable a more comprehensive analysis of the available alternatives with different patterns of uncertainty and vagueness.

Two practical applications were solved to demonstrate the proposed techniques show their applicability. In addition, the results are compared with the results of some existing methods for the verification and validation of the proposed techniques. The first example handles a warehouse location selection problem in which both the weights of the criteria and the ratings of the alternatives for the chosen criteria are expressed using SFSs. The results of the proposed methods are compared with the results of the SFTOPSIS of Gündoğdu and Kahraman (2019a) and the SF-VIKOR of Gündoğdu and Kahraman (2019b). The results obtained by the proposed SF-TOPSIS and SF-VIKOR coincide with the results of Gündoğdu and Kahraman's SF-VIKOR using three different distance measures namely, Euclidean distance, Spherical distance, and $\mathrm{Xu}$ and Zhang distance. The results also coincide with the results of Gündoğdu and Kahraman's SFTOPSIS utilizing $\mathrm{Xu}$ and Zhang distance.

The second example evaluates hydrogen storage systems for automobiles in which the weights of the criteria are type 1 fuzzy sets while the ratings of the alternatives for the evaluation criteria are crisp and linguistic variables. The results of the proposed methods are compared with the results of Gündoğdu and Kahraman's SF-TOPSIS and the F-AHP proposed by Gim and Kim (2014). The results of the proposed SF-TOPSIS coincide with the results of Gim and Kim's F-AHP. Meanwhile, in the proposed SFVIKOR the best solution remains the same, but the rest of the ranking list varies with different weights of "the maximum group utility" strategy. This is due to the apparent variation in the performance of the alternatives for the evaluation criteria and its effect on 
individual satisfaction. It was also found that the results of the proposed SF-TOPSIS and SF-VIKOR for $\gamma=0.9$ coincide with that of the SF-TOPSIS of Gündoğdu and Kahraman (2019) employing suitable combinations of distance measures and score functions such that the distance between the best and worst solutions is the largest.

As previously mentioned, since SFSs are three-dimensional with three independent degrees, the distance between the positive and negative ideal solutions is not guaranteed to be the largest between different alternatives. Therefore, in future research, reference point techniques need to be studied comprehensively to find the perfect matching between the proposed score functions and distance formulas such that the distance between the ideal solutions is the largest.

Sustainable supply chain management is considered one of the hot topics (Xiao et al. 2021). Sharaf and Khalil (2021) extended TODIM using SFSs for green occupational health and safety equipment supplier selection. For further research, various environmental problems in a supply chain with subjective data can be tackled by other MCDM techniques using SFSs.

\section{Compliance with Ethical Standards}

Conflict of Interest: The author declares that there is no conflict of interest.

Ethical approval: This article does not contain any studies with human participants or animals performed by the author.

\section{References}

Abdel-Baset M, Chang V, Gamal A, Smarandache F (2019) An integrated neutrosophic ANP and VIKOR method for achieving sustainable supplier selection: A case study in importing field. Computers in Industry 106: 94-110

Akram M, Adeel A (2019) TOPSIS Approach for MAGDM Based on Interval-Valued Hesitant Fuzzy N-Soft Environment. Int. J. Fuzzy Syst 21(3):993-1009.

Akram M, Alsulami S, Khan A, Karaaslan F (2020) Multi-Criteria Group DecisionMaking Using Spherical Fuzzy Prioritized Weighted Aggregation Operators. International Journal of Computational Intelligence System 13(1): 1429-1446.

Akram M, Kahraman C, Zahid K (2021a) Group decision-making based on complex spherical fuzzy VIKOR Approach. Knowledge-Based Systems 216, 106793.

Akram M, Kahraman C, Zahid K (2021c) Extension of TOPSIS model to the decisionmaking under complex spherical fuzzy information. Soft Computing 25:1077110795.

Akram M, Khan A, Alcantud JCR, Santos-García G (2021b) A hybrid decision-making framework under complex spherical fuzzy prioritized weighted aggregation operators. Expert Systems, 38:e12712. https://doi.org/10.1111/exsy.12712.

Alguliyev R, Aliguliyev R, Yusifov F (2020) Modified fuzzy TOPSIS + TFNs ranking model for candidate selection using the qualifying criteria. Soft Computing 24:681-695.

Al Zaabi H, Bashir H (2020) Modeling and analyzing project interdependencies in project portfolios using an integrated social network analysis-fuzzy TOPSIS 
MICMAC approach Int J Syst Assur Eng Manag.doi.org/10.1007/s13198-02000962-3.

Ashraf S, Abdullah S, Mahmood T, Ghani F, Mahmood T (2019) Spherical fuzzy sets and their applications in multi-attribute decision making problems. Journal of intelligent and fuzzy systems 36(3): 2829-2844.

Atanassov KT (1986) Intuitionistic fuzzy sets. Fuzzy Sets and Systems 20 (1): 87-96.

Awasthi A, Kannan G (2016) Green supplier development program selection using NGT and VIKOR under fuzzy environment. Computers \& Industrial Engineering 91: $100-108$.

Boltürk E (2020) AS/RS Technology Selection Using Spherical Fuzzy TOPSIS and Neutrosophic TOPSIS. In: C. Kahraman et al. (Eds.) INFUS 2019, AISC 1029: 969-976.

Boltürk E, Kahraman C (2018) A novel interval-valued neutrosophic AHP with cosine similarity measure. Soft Comput 22:4941-4958.

Chen T-Y (2018) Remoteness index-based Pythagorean fuzzy VIKOR methods with a generalized distance measure for multiple criteria decision analysis. Information Fusion 41: 129-150.

Chu T-C, Kysely M (2020) Ranking objectives of advertisements on Facebook by a fuzzy TOPSIS method. Electronic Commerce Research. doi.org/10.1007/s10660-01909394-Z.

Cui F-B, You X-Y, Shi H, Liu H-C (2018) Optimal siting of electric vehicle charging stations using Pythagorean fuzzy VIKOR approach. Mathematical Problems in Engineering. doi: 10.1155/2018/9262067.

Donyatalab Y, Farid F, Gundogdu FK, Farrokhizadeh E, Shishavan SAS, Kahraman C (2021) Distance and Similarity Measures Under Spherical Fuzzy Environment and Their Application to Pattern Recognition. Journal of Multiple-Valued Logic and Soft Computing 37(3-4):363-407.

Emeç S, Akkaya G (2018) Stochastic AHP and fuzzy VIKOR approach for warehouse location selection problem. Journal of Enterprise Information Management 31(6): 950-962.

Erdoğan M, Kaya I, Karaşan A, Çolak M (2021) Evaluation of autonomous vehicle driving systems for risk assessment based on three-dimensional uncertain linguistic variables. Applied Soft Computing 113, Part A, 107934.

Forouzandeh S, Berahmand K, Nasiri E, Rostami M (2021) A Hotel Recommender System for Tourists Using the Artificial Bee Colony Algorithm and Fuzzy TOPSIS Model: A Case Study of TripAdvisor. International Journal of Information Technology \& Decision Making 20(1): 399-429.

Garg H, Kumar K (2020) A novel exponential distance and its based TOPSIS method for interval-valued intuitionistic fuzzy sets using connection number of SPA theory. Artificial Intelligence Review 53:595-624.

Ghorabaee MK (2016) Developing an MCDM method for robot selection with interval type-2 fuzzy sets. Robot Comput Integr Manuf 37: 221-232.

Gim B, Kim JW (2014) Multi-criteria evaluation of hydrogen storage systems for automobiles in Korea using the fuzzy analytic hierarchy process. International Journal of Hydrogen Energy 39:7852-7858. 
Gul M, Ak MF, Guneri AF (2019) Pythagorean fuzzy VIKOR-based approach for safety risk assessment in mine industry. Journal of Safety Research 69: 135-153.

Gul M, Celik E, Aydin N, Gumus AT, Guneri AF (2016) A state of the art literature review of VIKOR and its fuzzy extensions on applications. Appl Soft Comput 46: 60-89.

Gul M, Guven B, Guneri AF (2018) A new fine-Kinney-based risk assessment framework using FAHP-FVIKOR incorporation. Journal of Loss Prevention in the Process Industries 53: 3-16.

Gül S (2021) Extending ARAS with Integration of Objective Attribute Weighting under Spherical Fuzzy Environment. International Journal of Information Technology \& Decision Making 20(3): 1011-1036.

Gündoğdu FK, Kahraman C (2019a) Spherical fuzzy sets and spherical fuzzy TOPSIS method. Journal of intelligent and fuzzy systems 36(1): 337-352.

Gündoğdu FK, Kahraman C (2019b) A novel VIKOR method using spherical fuzzy sets and its application to warehouse site selection. Journal of intelligent and fuzzy systems 37: 1197-1211.

Gündoğdu FK, Kahraman C (2019c) A novel fuzzy TOPSIS method using emerging interval-valued spherical fuzzy sets. Engineering Applications of Artificial Intelligence 85: 307-323.

Gündoğdu FK, Kahraman C (2020a) A novel spherical fuzzy QFD method and its application to the linear delta robot technology development. Engineering Applications of Artificial Intelligence 87:103348.

Gündoğdu FK, Kahraman C (2020b) A novel spherical fuzzy analytic hierarchy process and its renewable energy application. Soft Computing 24: 4607-4621.

Gupta P, Mehlawat MK, Grover N (2016) Intuitionistic fuzzy multi-attribute group decision-making with an application to plant location selection based on a new extended VIKOR method. Information Sciences 370-371: 184-203.

Hajek P, Froelich W (2019) Integrating TOPSIS with interval-valued intuitionistic fuzzy cognitive maps for effective group decision making. Information Sciences 485: 394-412.

Hamal S, Ozlem S (2021) A novel integrated AHP and MULTIMOORA method with interval-valued spherical fuzzy sets and single-valued spherical fuzzy sets to prioritize financial ratios for financial accounting fraud detection. Journal of Intelligent \& Fuzzy Systems. DOI: 10.3233/JIFS-219195.

Han H, Trimi S (2018) A fuzzy TOPSIS method for performance evaluation of reverse logistics in social commerce platforms. Expert Systems With Applications 103: $133-145$.

Hu J, Pan L, Chen X (2017) An Interval Neutrosophic Projection-Based VIKOR Method for Selecting Doctors. Cogn Comput 9:801-816.

Huang Y-H, Wei G-W, Wei C (2017) VIKOR Method for Interval Neutrosophic Multiple Attribute Group Decision-Making. Information 8:144, doi:10.3390/info8040144.

Hwang CL, Yoon K (1981) Multiple attributes decision making methods and applications. Springer, Berlin Heidelberg.

Hydrogen Storage Technical Team Roadmap (2017) www.energy.gov 
Karaşan A, Bolturk E, Kahraman C (2020) An Integrated Interval-Valued Neutrosophic AHP and TOPSIS Methodology for Sustainable Cities' Challenges. In: C. Kahraman et al. (Eds.) INFUS 2019, AISC 1029: 653-661.

Karaşan A, Kaya I (2020) Neutrosophic TOPSIS Method for Technology Evaluation of Unmanned Aerial Vehicles (UAVs). In: C. Kahraman et al. (Eds.) INFUS 2019, AISC 1029:665-673.789,-().

Khan MSA, Abdullah S, Ali A, and Amin F (2019) An extension of VIKOR method for multi-attribute decision-making under Pythagorean hesitant fuzzy setting. Granular Computing 4(3): 421-434.

Krishankumar R, Premaladha J, Ravichandran KS, Sekar KR, Manikandan R, Gao XZ (2020) A novel extension to VIKOR method under intuitionistic fuzzy context for solving personnel selection problem. Soft Computing 24:1063-1081.

Krishankumar R, Ravichandran KS, Premaladha J, Kar S, Zavadskas EK, Antucheviciene J (2018) A decision framework under a linguistic hesitant fuzzy set for solving multi-criteria group decision making problems. Sustainability 10(8), 2608.

Li H, Wang W, Fan L, Li Q, Chen X (2020) A novel hybrid MCDM model for machine tool selection using fuzzy DEMATEL, entropy weighting and later defuzzification VIKOR. Applied Soft Computing Journal 91: 106207

Liang W-Z, Zhao G-Y, Hong C-S (2018) Performance assessment of circular economy for phosphorus chemical firms based on VIKOR-QUALIFLEX method Journal of Cleaner Production 196: 1365-1378

Liao $\mathrm{H}, \mathrm{Xu} \mathrm{Z}$ (2014) multi-criteria decision making with intuitionistic fuzzy PROMETHEE. J Intell Fuzzy Syst. 27: 1703-1717.

Liu K, Liu Y, Qin J (2018) An integrated ANP-VIKOR methodology for supplier selection with interval type-2 fuzzy sets. Granul. Comput. 3(3): 193-208.

Luo X, Wang X (2017) Extended VIKOR Method for Intuitionistic Fuzzy Multi-attribute Decision-Making Based on a New Distance Measure. Mathematical Problems in Engineering 4072486:1-16. doi.org/10.1155/2017/4072486

Lupo T, Bellomo E (2019) DINESERV along with fuzzy hierarchical TOPSIS to support the best practices observation and service quality improvement in the restaurant Context. Computers \& Industrial Engineering 137: 106046.

Malakouti M, Faizi M, Hosseini S-B, Norouzian-Maleki S (2019) Evaluation of flexibility components for improving housing quality using fuzzy TOPSIS method. Journal of Building Engineering 22: 154-160.

Manna S, Basu TM, Mondal SK (2020) A soft set based VIKOR approach for some decision-making problems under complex neutrosophic environment. Engineering Applications of Artificial Intelligence 89:103432.

Mehdiyev N (2020) Application of Fuzzy TOPSIS for Credit Scoring. In: C. Kahraman et al. (Eds.) INFUS 2019, AISC 1029: 779-786.

Memari A, Dargi A, Jokar MRA, Ahmad R, Abdul Rahim A.R (2019) Sustainable supplier selection: A multi-criteria intuitionistic fuzzy TOPSIS method . Journal of Manufacturing Systems 50: 9-24.

Mete S, Serin F, Oz NE,4, Gul M (2019) A decision-support system based on Pythagorean fuzzy VIKOR for occupational risk assessment of a natural gas pipeline construction. Journal of Natural Gas Science and Engineering 71: 102979. 
Mousavi SM, Vahdani B, Behzadi SS (2016) Designing a model of intuitionistic fuzzy VIKOR in multi-attribute group decision - making problems. Iranian Journal of Fuzzy Systems 13(1): 45-65.

Narayanamoorthy S, Geetha S (2017) Intuitionistic hesitant fuzzy VIKOR method for multi-criteria group decision making. International Journal of Pure and Applied Mathematics 113 (9): $102-112$

Nilashi M, Samad S, Manaf AA, Ahmadi H, Rashid TA, Munshi A, Almukadi W, Ibrahim O, Ahmed OH (2019) Factors influencing medical tourism adoption in Malaysia: A DEMATELFuzzy TOPSIS approach. Computers \& Industrial Engineering 137:106005

Opricovic S (1998) Multicriteria optimization of civil engineering systems. PhD Thesis, Faculty of Civil Engineering, Belgrade.

Opricovic S (2011) Fuzzy VIKOR with an application to water resources planning. Expert Systems with Applications 38:12983-12990

Palczewskia K, Sałabuna W (2019) The fuzzy TOPSIS applications in the last decade. Procedia Computer Science 159: 2294-2303.

Pramanik S, Dalapati S, Alam S, Roy TK (2018) VIKOR Based MAGDM strategy under Bipolar Neutrosophic Set Environment. Neutrosophic Sets and Systems 19: 5769.

Rani P, Mishra AR, Mardani A, Cavallaro F, Alrasheedi M, Alrashidi A (2020a) A novel approach to extended fuzzy TOPSIS based on new divergence measures for renewable energy sources selection. Journal of Cleaner Production 257: 120352.

Rani P, Mishra AR, Rezaei G, Liao H, Mardani A (2020b) Extended Pythagorean Fuzzy TOPSIS Method Based on Similarity Measure for Sustainable Recycling Partner Selection Int. J. Fuzzy Syst. 22(2):735-747.

Rashidi K, Cullinane K (2019) A comparison of fuzzy DEA and fuzzy TOPSIS in sustainable supplier selection: Implications for sourcing strategy. Expert Systems With Applications 121: 266-281.

Ren Z, Xu Z, Wang H (2017) Dual hesitant fuzzy VIKOR method for multi-criteria group decision making based on fuzzy measure and new comparison method. Information Sciences 388-389:1-16.

Rouyendegh BD, Yildizbasi A, I Yilmaz I (2020) Evaluation of retail industry performance ability through integrated intuitionistic fuzzy TOPSIS and data envelopment analysis approach. Soft Computing. doi.org/10.1007/s00500-02004669-2.(0123456789

Salih MM, Zaidan BB, Zaidan AA, Ahmed MA (2019) Survey on fuzzy TOPSIS stateof-the-art between 2007 and 2017. Computers and Operations Research 104: 207227.

Sari K (2017) A novel multi-criteria decision framework for evaluating green supply chain management practices. Computers \& Industrial Engineering 105: 338-347.

Sarkar B, Biswas A (2020) A unified method for Pythagorean fuzzy multi-criteria group decision-making using entropy measure, linear programming and extended technique for ordering preference by similarity to ideal solution Soft Computing 24:5333-5344.

Seyedmohammadi J, Sarmadian F, Jafarzadeh AA, Ghorbani MA, Farzin Shahbazi F (2018) Application of SAW, TOPSIS and fuzzy TOPSIS models in cultivation 
priority planning for maize, rapeseed and soybean crops. Geoderma 310: 178190.

Sharaf IM (2019) Supplier selection using a flexible interval-valued fuzzy VIKOR. Granul. Comput. doi: 10.1007/s41066-019-00169-3.

Sharaf IM (2021a) Spherical Fuzzy VIKOR with SWAM and SWGM Operators for MCDM. In: Kahraman C, Kutlu Gündoğdu F (eds) Decision Making with Spherical Fuzzy Sets. Studies in Fuzziness and Soft Computing 392. Springer, Cham. https://doi.org/10.1007/978-3-030-45461-6_9.

Sharaf IM (2021b) Global Supplier Selection with Spherical Fuzzy Analytic Hierarchy Process. In: Kahraman C., Kutlu Gündoğdu F. (eds) Decision Making with Spherical Fuzzy Sets. Studies in Fuzziness and Soft Computing, vol 392. Springer, Cham. https://doi.org/10.1007/978-3-030-45461-6_14.

Sharaf IM, Khalil EAHA (2021) A spherical fuzzy TODIM approach for green occupational health and safety equipment supplier selection. International Journal of Management Science and Engineering Management 16(1): 1-13.

Smarandache F (1998) Neutrosophy: neutrosophic probability, set, and logic: analytic synthesis and synthetic analysis. American Research Press, Rehoboth.

Soner O, Celik E, Akyuz E (2017) Application of AHP and VIKOR methods under interval type 2 fuzzy environment in maritime transportation. Ocean Eng 129: 107-116.

Wang J, Wei G., Lu M (2018) An Extended VIKOR Method for Multiple Criteria Group Decision Making with Triangular Fuzzy Neutrosophic Numbers. Symmetry 10: 497, doi:10.3390/sym10100497.

Wei G, Wang J, Lu J, Wu J, Wei C, Alsaadi FE, Tasawar Hayat T (2019) VIKOR method for multiple criteria group decision making under 2-tuple linguistic neutrosophic environment. Economic Research-Ekonomska Istraživanja doi.org/10.1080/1331677X .2019.1691036

Xiao Q, Chen L, Xie M, Wang C (2021) Optimal contract design in sustainable supply chain: Interactive impacts of fairness concern and overconfidence. Journal of the Operational Research Society, 72 (7): 1505-1524.

Xu D, Li W, Ren X, Shen W, Dong L (2019) Technology selection for sustainable hydrogen production: A multi-criteria assessment framework under uncertainties based on the combined weights and interval best-worst projection method. International Journal of Hydrogen Energy. doi.org/ 10.1016/ j.ijhydene.2019.09. 030 .

Xue M, Tang X, Feng N (2016) An Extended VIKOR Method for Multiple Attribute Decision Analysis with Bidimensional Dual Hesitant Fuzzy Information. Mathematical Problems in Engineering, 4274690:1- 16.

Yager RR (2014) Pythagorean membership grades in multi-criteria decision-making. IEEETrans Fuzzy Syst 22(4): 958-965.

Yalcin AS, Kilic HS, Guler E (2020) Research and Development Project Selection via IF-DEMATEL and IF-TOPSIS. In: C. Kahraman et al. (Eds.) INFUS 2019, AISC 1029: 625-633. 
Yazdani M, Graeml FR (2014) VIKOR and its applications: A state-of-the-art survey. International Journal of Strategic Decision Sciences 5(2): 56-83.

Yu C, Shao Y, Wang K, Zhang L (2019) A group decision making sustainable supplier selection approach using extended TOPSIS under interval-valued Pythagorean fuzzy environment Expert Systems With Applications 121:1-17.

Yucesan M, Gul M (2020) Hospital service quality evaluation: an integrated model based on Pythagorean fuzzy AHP and fuzzy TOPSIS. Soft Computing 24:3237-3255.

Zadeh LA (1965) Fuzzy sets. Inf Control 8(3): 338-353.

Zadeh LA (1975) The concept of a linguistic variable and its applications to approximate reasoning. Inf Sci 8:199-249.

Zeng S, Chen S-M, Kuo L-W (2019) Multi-attribute decision making based on novel score function of intuitionistic fuzzy values and modified VIKOR method. Information Sciences 488: 76-92.

Zhang C, Chen C, Streimikiene D, Balezentis T (2019) Intuitionistic fuzzy MULTIMOORA approach for multi-criteria assessment of the energy storage technologies. Applied Soft Computing Journal 79: 410-423.

Zhao J, You X-Y, Liu H-C, Wu S-M (2017) An extended VIKOR method using intuitionistic fuzzy sets and combination weights for supplier selection. Symmetry 9(9): 169. doi:10.3390/sym9090169.

Zhou F, Wang X, Goh M (2018) Fuzzy extended VIKOR based mobile robot selection model for hospital pharmacy. International Journal of Advanced Robotic Systems 15(4): $1-11$. 


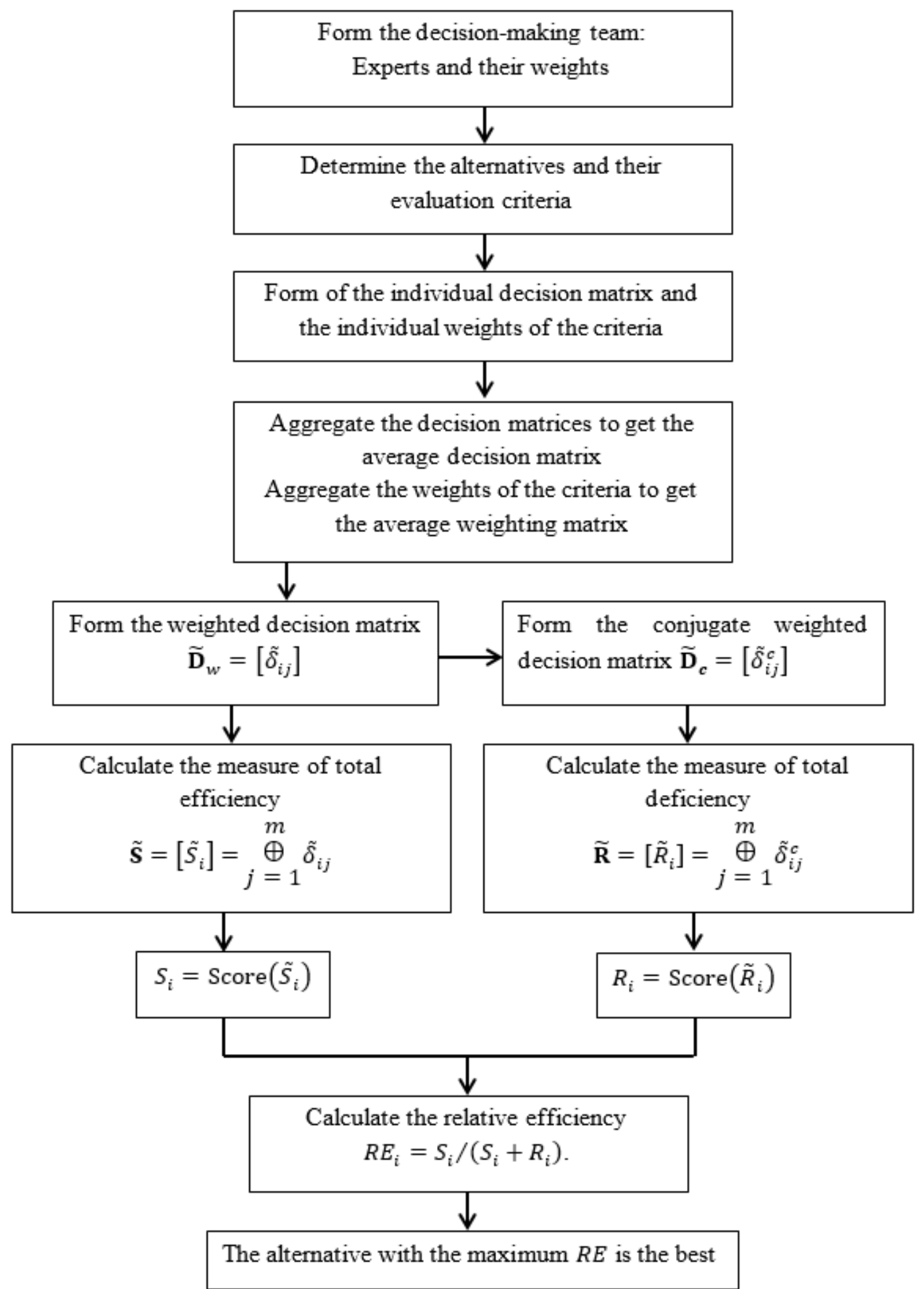

\section{Figure 1}

The flowchart of the proposed SF-TOPSIS 


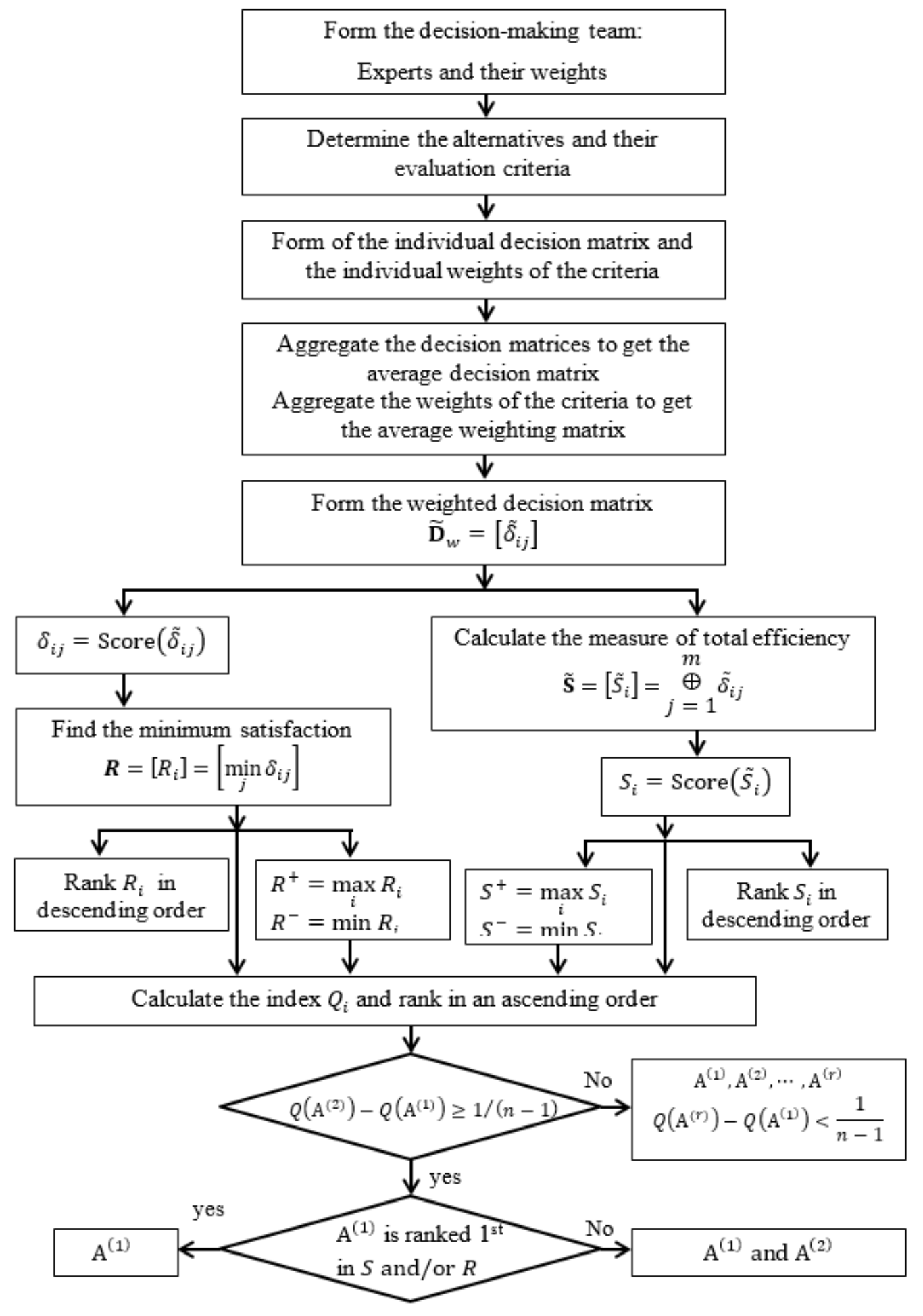

\section{Figure 2}

The flowchart of the proposed SF-VIKOR 